NBER WORKING PAPER SERIES

\title{
PUBLIC SECTOR PERSONNEL ECONOMICS: WAGES, PROMOTIONS, AND THE COMPETENCE-CONTROL TRADE-OFF
}

\author{
Charles M. Cameron \\ John M. de Figueiredo \\ David E. Lewis \\ Working Paper 22966 \\ http://www.nber.org/papers/w22966 \\ NATIONAL BUREAU OF ECONOMIC RESEARCH \\ 1050 Massachusetts Avenue \\ Cambridge, MA 02138 \\ December 2016
}

We thank Bob Gibbons, Guido Tabellini, Bentley MacLeod, Pablo Spiller, Bob Powell, Steve Tadelis, Oliver Williamson, Noam Yuchtman, Ernesto Dal Bo, Ken Shepsle, Nolan McCarty and seminar participants at Vanderbilt, Duke, Princeton, the Institute for Advanced Study, and the Haas School of Business (Berkeley) for helpful comments. This research was funded by NSF Grant numbers 1061575, 1061600, and 1061512. The views expressed herein are those of the authors and do not necessarily reflect the views of the National Bureau of Economic Research.

NBER working papers are circulated for discussion and comment purposes. They have not been peer-reviewed or been subject to the review by the NBER Board of Directors that accompanies official NBER publications.

(C) 2016 by Charles M. Cameron, John M. de Figueiredo, and David E. Lewis. All rights reserved. Short sections of text, not to exceed two paragraphs, may be quoted without explicit permission provided that full credit, including $(\odot$ notice, is given to the source. 
Public Sector Personnel Economics: Wages, Promotions, and the Competence-Control Trade-off Charles M. Cameron, John M. de Figueiredo, and David E. Lewis

NBER Working Paper No. 22966

December 2016

JEL No. H11,J24,J45,K2

\begin{abstract} and expertise acquisition.

Charles M. Cameron

Princeton University

Woodrow Wilson School

030 Corwin Hall

Princeton, NJ 08544-1013

ccameron@princeton.edu

John M. de Figueiredo

The Law School and Fuqua School

Duke University

210 Science Drive, Box 90360

Durham, NC 27708

and NBER

jdefig@duke.edu

David E. Lewis

Vanderbilt University

333 Commons Center

Nashville, TN 37203-5721

david.lewis@vanderbilt.edu
\end{abstract}

We model personnel policies in public agencies, examining how wages and promotion standards can partially offset a fundamental contracting problem: the inability of public sector workers to contract on performance, and the inability of political masters to contract on forbearance from meddling. Despite the dual contracting problem, properly constructed personnel policies can encourage intrinsically motivated public sector employees to invest in expertise, seek promotion, remain in the public sector, and develop policy projects. However, doing so requires internal personnel policies that sort "slackers" from "zealots." Personnel policies that accomplish this task are quite different in agencies where acquired expertise has little value in the private sector, and agencies where acquired expertise commands a premium in the private sector. Finally, even with well-designed personnel policies, there remains an inescapable trade-off between political control 


\section{Introduction}

Public sector bureaucracies play a vital role in democracies, because they implement the programs and deliver the services desired by the electorate. Unfortunately, achieving high performance in public sector agencies is notoriously difficult. The source of the difficulty is a dual contracting problem between the civil servants employed in public agencies and the politicians who run or oversee them. On the one hand, the parties can rarely contract on the effort or performance of the civil servants; on the other, the parties can never fully contract on the forbearance from self-interested meddling by the politicians. Together, these two contracting problems make high performance elusive in many agencies. Nonetheless, some agencies do achieve high performance. We argue that a key factor in their success is designing internal personnel policies - especially wage and promotion standards - that build cadres of highly motivated and capable managers. In this paper we offer a model suggesting how to design government personnel policies.

The bases of the two contracting problems in public agencies are well-known (Wilson 1989). First, performance contracting in public agencies is frequently problematic. The goals of national security agencies, prisons, schools, police forces, welfare agencies, the diplomatic corps, inter-governmental grant programs, and even park services and transportation departments are inherently multi-dimensional and imprecise. The tasks performed in the agencies are typically resistant to easy measurement and only tenuously connected to formal organizational missions. As is now well-understood, this cluster of characteristics makes performance contracting very difficult or even counter-productive (Holmstrom and Milgrom 1991, Baker 2002). In addition, self-binding efforts by politicians to protect employees from the grossest varieties of political meddling, in the form of civil service prohibitions on easy dismissal and salary manipulation, limit the use of high-powered incentives in public agencies (Johnson and Liebcap 1994, Maranto 1998, Maranto 2001). So do public sector unions, which adamantly oppose performance contracting (West 2009, Moe 2011).

Second, political meddling in public agencies is pervasive and unavoidable (Moe 1985, 
McNollgast 1989, McCarty 2004). Citizens in democracies demand accountability and responsiveness from public agencies. Politicians, as agents of the electorate, become the principals of the agencies, either directly (when the agency is actually administered by a politician or political appointee) or indirectly (when politicians approve budgets and craft enabling legislation). As the effective "boss," the politician-principal can no more contract away her decision rights in the agency than a CEO can in a firm (Baker, Gibbons, Murphy 1999). And, inevitably the politician-principal will be tempted to use those decision rights to further her own objectives. Not only does this meddling subvert agency missions, it undercuts the motivation of employees in the agency and can dramatically degrade agency performance (Lewis 2008).

There are solutions to the dual contracting problem. First, agencies like firms can build corporate cultures through relational contracts (Williamson 1985, Williamson 1996, Baker, Gibbons, Murphy 1999, MacLeod 2007). In stable environments, these relational contracts can mitigate the performance contracting problem in public agencies (Kaufman 1960). They can also reduce or offset the meddling problem (Carpenter 2001, Carpenter 2010). However, this solution requires the political principal and the public sector agents to engage in longterm, repeated interactions. In public agencies, governments are short-lived and political appointees often even shorter-lived (Heclo 1977, O’Connell 2009, Dull et al 2012). Short tenures render self-enforcing relational contracts nugatory.

A second alternative is to attract and then differentially promote or retain intrinsicallymotivated individuals ("zealots") who - in contrast with purely financially-motivated "slackers" - find employment as public sector managers inherently satisfying. Of course, reliance on intrinsic motivation is also possible in the private sector (Prendergast 2008). But it plays a prominent role in the public sector, as many have observed (Downs 1967, Kaufman 1981, Perry and Wise 1990, Golden 2000, Besley and Ghatak 2005, Gailmard and Patty 2007).

If public agencies are to mitigate the dual contracting problem by attracting and differentially promoting and retaining zealots, the agencies must have properly designed personnel 
policies. What do such personnel policies in public agencies look like and how do they operate? These are the questions we address in this paper.

The starting place for our analysis of public sector personnel policies is the following observation: Although politicians and employees cannot contract on agent effort or principal forbearance, they can contract on two other dimensions, public sector wages and promotion standards. Indeed, civil service wage scales are well-defined public information, and promotion standards are generally written and transparent. Moreover, courts have demonstrated a willingness to use labor and employment laws to enforce agreements on wages and promotion standards. This offers the possibility of using wage scales and promotion standards strategically to attract zealots and sort them internally from slackers, even in the face of the non-contractible meddling problem.

Our analysis distinguishes two types of agencies or bureaus. "Type I" agencies are government organizations in which the skills of the professionals and managers have low value outside the agency. Type I civil servant positions include mail sort managers at the Post Office, conductors at Amtrak, office managers at the Department of Motor Vehicles, meat inspectors at the Department of Agriculture, social workers in the Department of Human Services, auction managers at the Bureau of Public Debt, and air traffic controllers at the Federal Aviation Administration. In these agencies, employee skills acquired in the public sector are specific to the public sector and do not command a wage premium in the private sector. "Type II" agencies are those government organizations in which the skills of the professionals and managers have high value in the private sector. Examples of Type II agency public sector positions include employment discrimination and antitrust attorneys in the Department of Justice, securities regulators, procurement officers in the Defense Department, aerospace engineers at NASA, and bank examiners at the Office of the Comptroller of the Currency. In such agencies, the skills acquired in the public sector are highly valued by private sector employers.

We argue that personnel policies should differ dramatically in these two environments. 
In Type I agencies, employees that enter the agency cannot depart for higher paying jobs in the private sector. Consequently, most become public sector "lifers." In this setting, the key problem is to motivate the zealots - and only the zealots - to seek promotion as agency managers, since their high motivation will lead them to work diligently in pursuit of the agency mission. We show that it is possible to craft a promotion standard and managerial wage that differentially induces zealots to invest in technical and policy expertise and become high quality managers, even in the face of political meddling. Slackers remain in the lower tiers of the agency as "clerks." We call this sorting behavior "promotion screening." In contrast, in Type II agencies employees that invest in expertise develop a skill set that commands a premium in the private sector. Thus, both slackers and zealots have an incentive to invest in expertise. The challenge for the Type II agency is to differentially retain the zealots post-promotion. We show that appropriately constructed wage ladders and promotion standards can induce sorting, but in this case "managerial sorting" in which the slackers opportunistically depart the agency as "in-and-outers" while zealots remain as agency managers.

The distinctively different personnel policies in the two types of agencies result in different wage structures, different promotion standards, different career paths, different politicization levels, and different rates of agency policy innovation. For example, Type II agencies will display substantially more turnover than Type I agencies. In Type II bureaus, the departures of slackers will tend to occur after investments in a level of expertise. In addition, wage schedules will be steeper, and managerial wages higher, in Type II bureaus than to Type I bureaus.

Illustrative Example.-Two bureaus in the same agency, the Department of the Treasury, illustrate the two different internal labor markets (ILMs) in action. The first bureau, the Office of Public Debt (OPD), is responsible for designing and executing the U.S. Treasury Bond auctions, operating direct bond sales to U.S. citizens, and keeping accounting records for the U.S. debt. Employees in this agency are promoted based on their ability to 


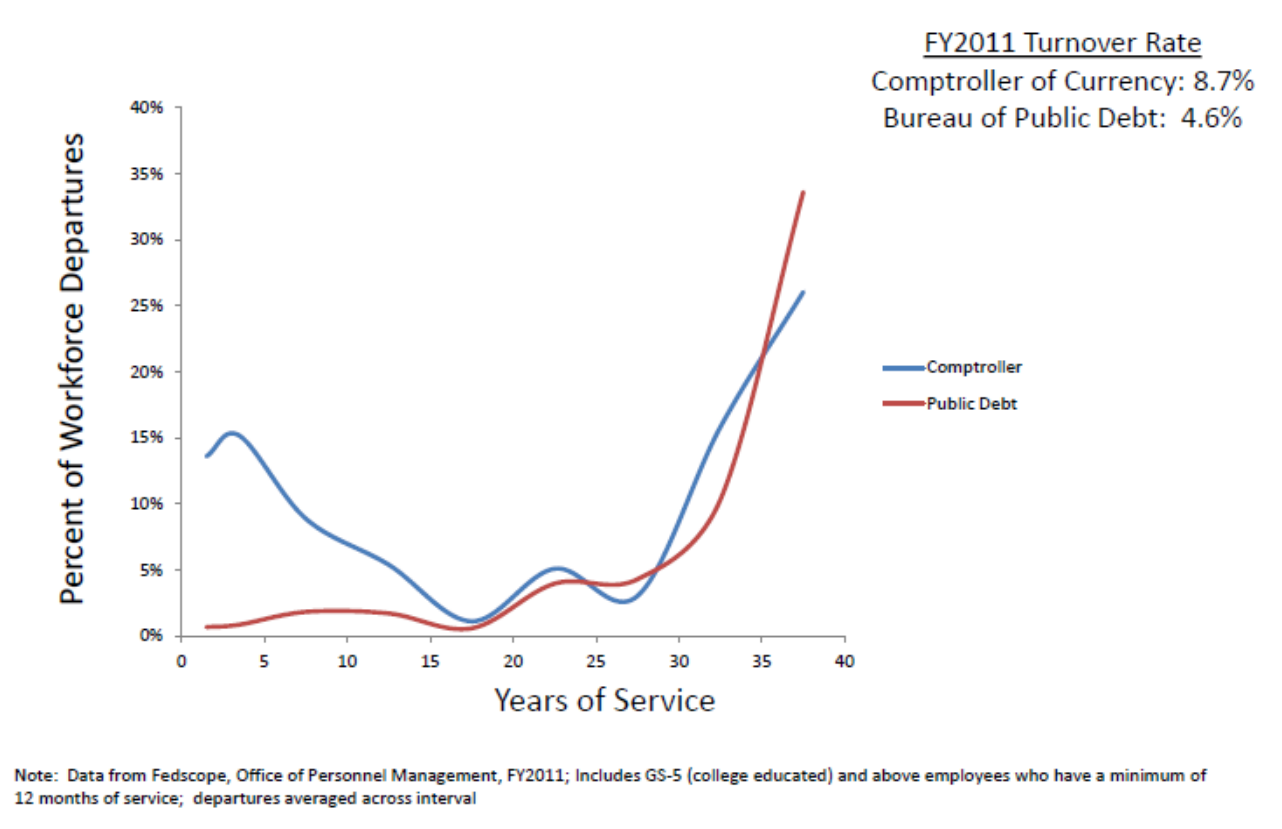

Figure 1: Turnover in Two Bureaus in the Treasury Department

effectively execute and manage these tasks. The skills in this agency, while crucial to the effective financing of the U.S. government, have limited value in the private sector. Hence, we categorize the Office of Public Debt as a Type I bureau. On the other hand, the Office of the Comptroller of the Currency (OCC) is a key player in bank regulation. Its bank examiners develop skills to assess regulatory compliance and the financial worthiness of the institutions under the OCC's control. Within the first few years of their career, the examiners are expected to pass a rigorous three-part Uniform Commissioned Examination. Thus, bank examiners develop a series of skills, including risk management, evaluation of asset safety and soundness, and how to manage a bank from a bank manager's perspective, all skills which have high value in the private sector. We categorize the OCC as a Type II bureau.

The employee turnover rate at the OCC is almost twice the turnover rate at OPD. In $2011,4.6 \%$ of all employees from the OPD departed government service while $8.7 \%$ of all employees in the OCC departed. In Figure 1, we disaggregate the FY2011 departures by years of service in the federal government for all employees with over one year of service. Figure 1 shows the employee departures from each agency as a percentage of total employees 
at the agency with the same job tenure in FY2011. The Figure illustrates two different patterns. First, OPD employees tend to be lifers. They have very low civil service departure rates in the first 20 years of their career. Between 20 and 30 years of service, there is a greater hazard of civil service exit as generous pension benefits vest. After 30 years of service, there are very high rates of departures as most of these employees end their working careers and enter retirement. At OCC, the pattern of departures is quite different. There is substantial churn in employment in the first ten years of employment, a low level between ten and twenty years of service, and similar pattern to the OPD after 20 years of service. It is precisely in the first few years of employment that OCC bank examiners sit for the Uniform Commissioned Examination and reveal to the private sector their expertise in skills that are valuable to the private sector - the same time that many of these individuals depart the OCC. Finally, $8 \%$ of employees at the OPD with 20-25 years of civil service tenure earn more than $\$ 150,000$, while $38 \%$ of employees at the OCC with $20-25$ years of civil service tenure at these same levels.

This example illustrates the different patterns of wages and turnover in Type I and Type II agencies. However, in both kinds of agencies, interference by a political appointee is also important and will alter agency performance by changing internal personnel policies. In equilibrium, politicization decreases the intensity of policy-making effort by civil servants, lowers the agency's promotion standards, decreases the acquisition of expertise by civil servants, flattens the agency's salary structure, and reduces the agency's policy activism.

The paper is organized as follows. In the next section, we present a model of public sector personnel policies in Type I and Type II agencies with slackers and zealots. Section III details equilibria in the multistage game and describe how sorting and screening occurs. We conclude with some numeric examples. In Section IV, we examine the managerial competence-control trade-off. We offer a final discussion and conclusion in Section V. Appendix A contains longer proofs and Appendix B contains a table of notation. 


\begin{tabular}{|l|l|}
\hline \multicolumn{1}{|c|}{ Exogenous } & \multicolumn{1}{c|}{ Endogenous } \\
\hline Agency Structure: 2 Level Job Ladder & Politicization by Boss \\
\hline Boss-Worker Policy Disagreement & Expertise Acquisition by Workers \\
\hline Private Sector Wages & Promotion Standard \\
\hline Size of Policy Wins/Losses & Public Sector Wages \\
\hline Cost Parameters (training, policy effort) & Policy-making Effort by Workers \\
\hline Intrinsic Motivation of Zealots & Probability of Policy Innovations \\
\hline & Stay/Exit Decisions by Workers \\
\hline & Manager job satisfaction \\
\hline
\end{tabular}

Table 1: What the Model of Public Sector Personnel Policies Does

\section{The Model}

The model has three distinct components: 1) policy-making, 2) the internal labor market, and 3) agency design. The policy-making component of the model draws heavily on Gailmard and Patty 2007. However, that paper treats policy-making as setting a point in ideological space, as is standard in positive political theory (see e.g., Epstein and O'Halloran 1999, Huber and McCarty 2004, Huber and Shipan 2002). In contrast, our analysis of policy-making closely follows Baker, Gibbons, Murphy 1999 and other papers in Organizational Economics by focusing on decisions over "projects." We see this modeling technology as somewhat more descriptive of policy-making in bureaucracies; arguably, it is somewhat more flexible as well. The ILM component of the model draws on perspectives from Personnel Economics (Oyer and Lazear 2013, Waldman 2013). Investment in human capital for promotion is important in the model, as it is in Prendergast 1993. However, sorting slackers and zealots post-employment lies at the heart of our model of internal personnel policies. In that sense, the model addresses questions raised at the end of Prendergast 2008 and complements the initial employment sorting studied in Besley and Ghatak 2005. The agency design component is a relatively straightforward exercise in contract theory (Bolton 2004).

As an overview, Table 1 indicates what is exogenous and what is endogenous in the model. 


\section{A. Sequence of Play, Information, and Strategies}

The players are the head of an agency (the Boss), assumed to be a political appointee, and a potential employee of the agency (the Subordinate). The Subordinate may be of two types denoted by $\theta \in\{0,1\}$, a "slacker" $(\theta=0)$ or a "zealot" $(\theta=1)$. The significance of this distinction will become clearer momentarily, when we detail utility functions, but while both value wages only zealots value policy. Subordinate type is private information for the Subordinate.

There are two jobs for Subordinates within the agency, the two forming a career ladder: an entry-level "clerk" position, and a policy-making "manager" position. In the former, the subordinate performs a routine task yielding benefit $v$ to the Boss. In the latter position, the manager works to create a policy initiative, a "project," to recommend to the Boss. If accepted by the Boss, a policy project yields payoffs $X$ to the Subordinate and $Y$ to the Boss. For simplicity we assume that the benefits take only two values, positive or negative: $X_{H}>0>X_{L}$ and $Y_{H}>0>Y_{L}$. Importantly, the project payoffs may differ systematically between the two players, so there is a tension between the preferences of the Subordinate and those of the Boss. The probability of $X_{H}$ is simply the Subordinate's work effort $a$.The conditional probability that the Boss's payoff is $Y_{H}$ when the Subordinate's payoff is $X_{H}$ is $p=\operatorname{Pr}\left(Y_{H} \mid X_{H}\right)$; the conditional probability that the Boss's payoff is $Y_{H}$ when the Subordinate's payoff is $X_{L}$ is $q=\operatorname{Pr}\left(Y_{H} \mid X_{L}\right)$. Thus, $p$ and $1-q$ indicate the similarity between the interests of the two players $(1-q$ will not play a major role in what follows but $p$ is extremely important). Rejected proposals bring a zero policy payoff to both players, as does no recommendation.

The sequence of play in the model is shown in Figure 2. Nature selects the Subordinate's type $\theta$ with common knowledge probability $\lambda$ (the probability of being a zealot). The Boss offers an employment contract specifying wages in both the clerk and manager jobs $\left(w_{C}\right.$ and $w_{m}$, respectively) and a promotion standard $\bar{e}$ based on a promotion evaluation. In addition, the Boss decides upon a level of politicization $\pi$ for the agency. ${ }^{1}$ Politicization connotes 
a centralized capacity for independent review of a recommended project. ${ }^{2}$ If the potential employee accepts employment, he enters the clerk-level job where he performs routine work and receives the wage $w_{C} \cdot{ }^{3}$ More importantly, though, as a clerk the Subordinate may invest in human capital or expertise $e \in[0, \infty)$ at cost $c(e)$. The clerk then undergoes a promotion evaluation, which effectively measures his agency-specific expertise $e$. If the clerk meets the promotion standard $\bar{e}$, he is promoted to manager; if not, he remains a clerk. In either case, the employee may then exit the agency in favor of employment in the private sector. ${ }^{4}$ If promoted to manager and deciding to stay in public employment, the subordinate (now a manager) decides upon a level of work effort $a \in[0,1]$ at cost $c(a, e)$, crafting a policy project. We define the Subordinate's work intensity as the probability of discovering a good project, so that $a=\operatorname{Pr}\left(X_{H}\right)$.

The effort cost of crafting a good project $c(a ; e)$ depends on the manager's expertise, so that more expert managers can undertake the same level of work effort at a lower cost to themselves. Given the results of his work, the manager may recommend the project to the Boss, or may decline to do so. ${ }^{5}$ If the manager recommends the project, the Boss probabilistically learns the payoffs from the project, depending on the level $\pi$ of politicization in the agency. Hence, increased "politicization" boosts the likelihood of an informed policy review under the independent control of the Boss. The Boss then accepts or rejects the manager's recommendation. Payoffs then accrue.

Because promoted managers can exit for private sector employment, we must specify the wages that they can earn in the private sector. Indeed this outside wage, $s_{i}$, plays an important role in the analysis. We specify private sector wages parametrically, focusing on two polar cases. In the first, the human capital acquired by the agency employee is of little value to private sector employees. For instance, the skills of policy makers in a Department of Motor Vehicles are not likely to be valued by private sector employers. In this case $s_{i}$ is not increasing in $e$. We assume $s_{i}=s_{c}$, the clerk-level wage in the private sector (an extreme assumption but one that captures the essential wage dynamic). We call agencies 


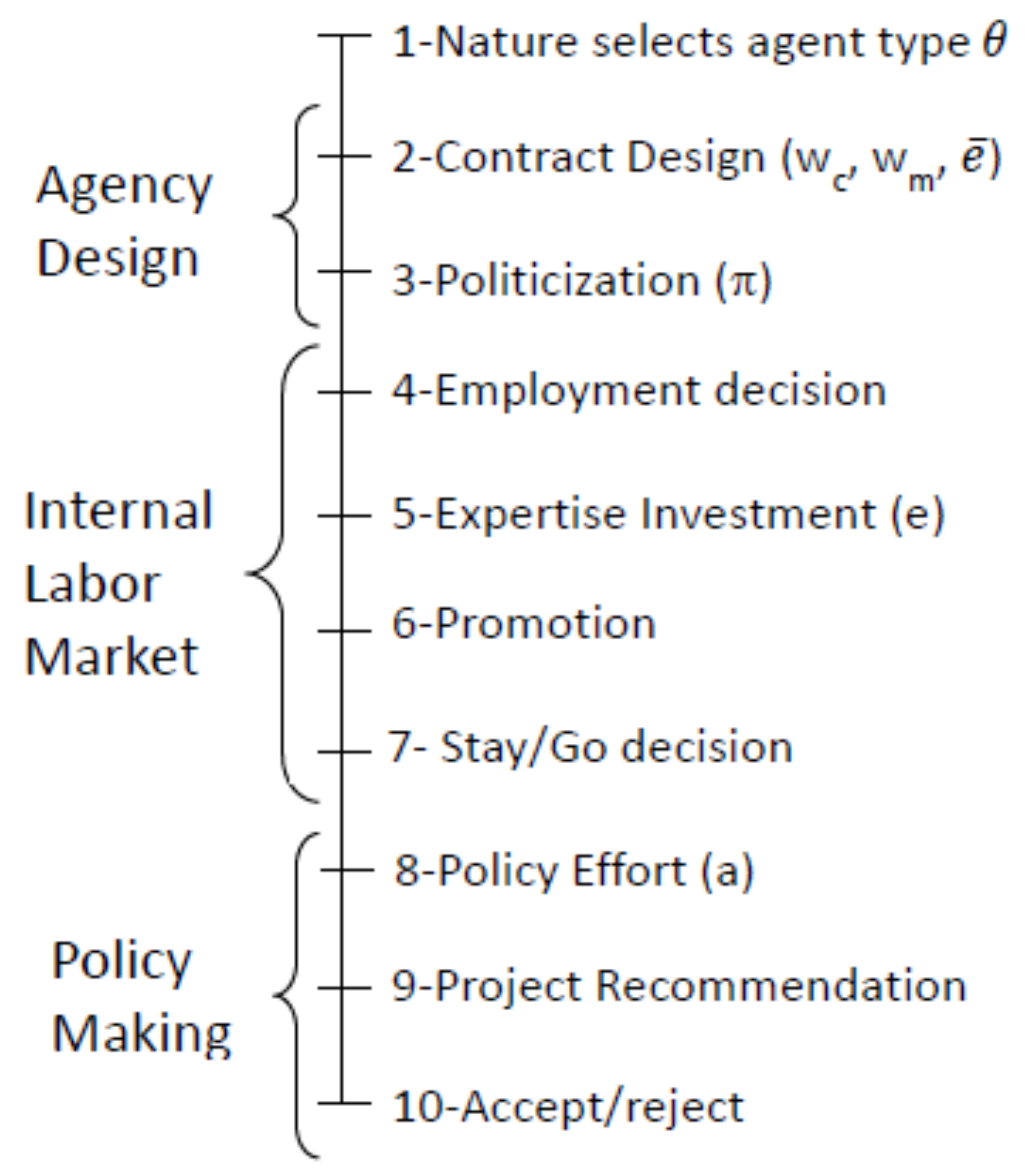

Figure 2: The Sequence of Play in the Game. 
like this "Type I" agencies. In the second case, the skills, knowledge, and contacts acquired by agency managers are very valuable to private sector employers, who hire the exiting public sector manager at an "in-and-outer" wage $s_{o}$. For instance, the knowledge of antitrust policy makers in the Department of Justice may command a considerable premium in the private sector. Here $s_{i}=s_{0}(e)$ is increasing in $e$. We call agencies like this "Type II" agencies. To complete the public-private comparison, we assume there is a mature second period private sector wage $s_{m}$ for career private-sector employees. For employees of Type I agencies, $s_{i}=s_{c}<s_{m}$. For employees of Type II agencies, $s_{c}<s_{m}$ but $s_{i}=s_{o}(e) \geq s_{m}$ for sufficiently high $e$ : a highly skilled in-and-outer may command as high or higher private sector wage than a career private sector manager.

It will be seen that the game has 10 distinct stages that can be grouped into three broad modules. Module 1 concerns agency design, and involves designing the "contract" offered employees and the selection of a level of politicization by the political appointee heading the agency. Module 2 addresses the agency's internal labor market, and details the workers' initial employment decision, employees' investment in expertise, the agency's promotion decision, and employee's decision to remain with the agency or depart for the private section. Module 3 examines policy making in the agency, focusing on the policy-making effort of managers, their recommendations, and the agency head's response. We divide the game into periods 1 and 2. The first period includes the first two modules, the second the third.

The following are common knowledge: outside wages $\left(s_{c}, s_{m}\right.$, and $s_{i}$ [either $s_{c}$ or $\left.s_{o}\right]$ ), the extent of policy agreement between the Boss and Subordinate $(p, 1-q)$ ), the value of projects $\left(X_{L}, X_{H}, Y_{L}, Y_{H}\right)$ and the cost functions $c(e)$ and $c(a ; e)$. The promotion standard $\bar{e}$, the wages $w_{c}$ and $w_{m}$, and the chosen level of politicization $\pi$ are observed by potential employees, and this is common knowledge. The promotion evaluation reveals the employee's human capital $e$ to the Boss but a potential outside employer can only observe whether the employee was promoted or not. The subordinate's policy effort $a$ is not observed by the Boss (otherwise, managerial wages could be contractible in policy effort). 
For the Subordinate, strategies include 1) a contract acceptance strategy; 2) an expertise investment strategy $e ; 3$ ) an exit or stay strategy following the outcome of the promotion evaluation; 4) a policy effort strategy a (for promoted employees who remain with the agency); and 5) a policy recommendation strategy $r$. For the Boss strategies include 1) a clerk wage strategy setting $\left.w_{c} ; 2\right)$ a manager wage strategy setting $\left.w_{m} ; 3\right)$ a promotion standard strategy setting $\bar{e}$; 4) a politicization strategy setting $\pi$, and 5) a decision strategy $d$ for policy recommendations.

\section{B. Utilities}

The payoffs to the Boss and Subordinate are the sum of the payoffs accruing in Periods 1 and 2 .

For the Boss, the period 1 payoff is

$$
u_{1}^{B}=\left\{\begin{array}{l}
v-w_{c} \text { if the worker accepts the contract } \\
0 \text { if the worker rejects the contract }
\end{array}\right.
$$

where $v$ is the value to the Boss of clerk services. The Boss's period 2 payoff is

$$
u_{2}^{B}=\left\{\begin{array}{l}
0 \text { if the worker accepted the contract but leaves } \\
v-w_{c} \text { if the worker accepted, was not promoted and stays } \\
r d Y-w_{m} \text { if the worker accepted, was promoted and stays }
\end{array}\right.
$$

where $r$ is the manager's project recommendation (either 0 or 1 ), $d$ is the Boss's decision on the recommendation (either 0 or 1 ), and $Y$ is the value to the Boss of the project (either $Y_{L}$ or $\left.Y_{H}\right){ }^{6}$

For the Subordinate, the period 1 payoff is

$$
u_{1}^{s}=\left\{\begin{array}{l}
w_{c}-c(e) \text { if the worker accepts the contract } \\
s_{c} \text { if the worker rejects the contract }
\end{array}\right.
$$


The period 2 payoff is

$$
u_{2}^{s}=\left\{\begin{array}{l}
s_{m} \text { if contract rejected in period } 1 \\
s_{c} \text { if contract accepted, not promoted, and left } \\
w_{c} \text { if contract accepted, not promoted, and stayed } \\
s_{i} \text { if contract accepted, promoted, and left } \\
w_{m}+\theta r d X-c(a ; e) \text { if contract accepted, promoted, and stayed }
\end{array}\right.
$$

where again $r$ is the recommendation and $d$ is the Boss's decision on the recommendation.

In what follows, we impose considerable structure on the two cost functions and (as explained above) the outside wages. In particular we assume that the cost of expertise investment $c(e)=k e^{2}$ (so $c(0)=0, c^{\prime}>0$ and $c^{\prime \prime}>0$ when $e>0$ ), and we assume the cost of work effort $c(a, e)=\gamma a^{2}$ where $\gamma=1 / e$. For Type I agencies, we assume outside wage $s_{i}=s_{c}$ so investment in policy expertise brings no increase in outside wages. For Type II agencies, we assume $s_{i}=s_{o}(e)=s_{c}+\kappa e^{2}$ so that $s_{o}(0)=s_{c}$ but (demonstrated) policy expertise boosts outside wages. Both are polar assumptions but distinguish clearly between two wage dynamics.

Intrinsic Motivation. - The utility function in Equation 1 embeds a distinct notion of non-pecuniary motivation: some public sector employees - zealots $(\theta=1)$ - internalize a sense of organizational mission and receive satisfaction from furthering that mission in the decisions over which they bear responsibility. Thus, they "take ownership" of agency decisions in their bailiwick. ${ }^{7}$ In contrast, slackers $(\theta=0)$ do not internalize the agency's mission and do not take ownership of the decisions in their domain of responsibility; their motivation is purely pecuniary. Hence, in Equation 1, a promoted zealot with policy responsibility has a term in his utility function, $r d X$, that a similarly positioned slacker does not. We further assume zealots do not take ownership of decisions over which they have no responsibility, for example, if they are never employed by an agency they do not internalize its mission 
and do not feel responsible for its decisions (though they may agree or disagree with them). Consequently, a zealot who pursues a purely private sector career does not have the term $r d X$ in his utility function. And, we assume a promoted zealot who leaves the agency does not have this term in his utility function once he becomes a private sector employee. This may be rationalized in two ways. First, the feeling of ownership of agency decisions, even in one's former bureau, is likely to decay over time given separation from the the agency. In a two-period model, we capture this decline in stylized form with very fast discounting. Second, the vacancy in the management position prevents the agency from implementing a project, so that $X=0 .{ }^{8}$

This form of non-pecuniary motivation - "decision ownership" - in somewhat novel (however see Vlaicu and Whallen 2012). But it is very closely related to "mission satisfaction" which arises from project success when a worker is employed by an agency with a valued mission (Besley and Ghatak 2005). However, decision ownership allows for a degree of policy conflict between the manager and an agency head. Formally, decision ownership is quite similar to standard non-pecuniary aspects of a job, such as flexible hours or on-site day care, that are valued by some employees but not others (Lazear 1998, Chapter 14) and may be analyzed in a similar way. The assumption that zealots internalize agency missions, rather than arrive with their own sense of mission, has ties with the literature on identity and organizations (Akerlof and Kranton 2005). This assumption allows us to sidestep ideological sorting across agencies by committed ideologues, but this is clearly an avenue for future research.

\section{Career Paths and Wage Ladders}

Figures 3 and 4 trace possible career paths and facilitating comparisons of wages.

The critical feature of the Type I environment is that a promoted public sector manager cannot depart the agency for a well-paying job in the private sector, as his investment in expertise has little outside value. In the extreme, his only outside option is an entry-level 


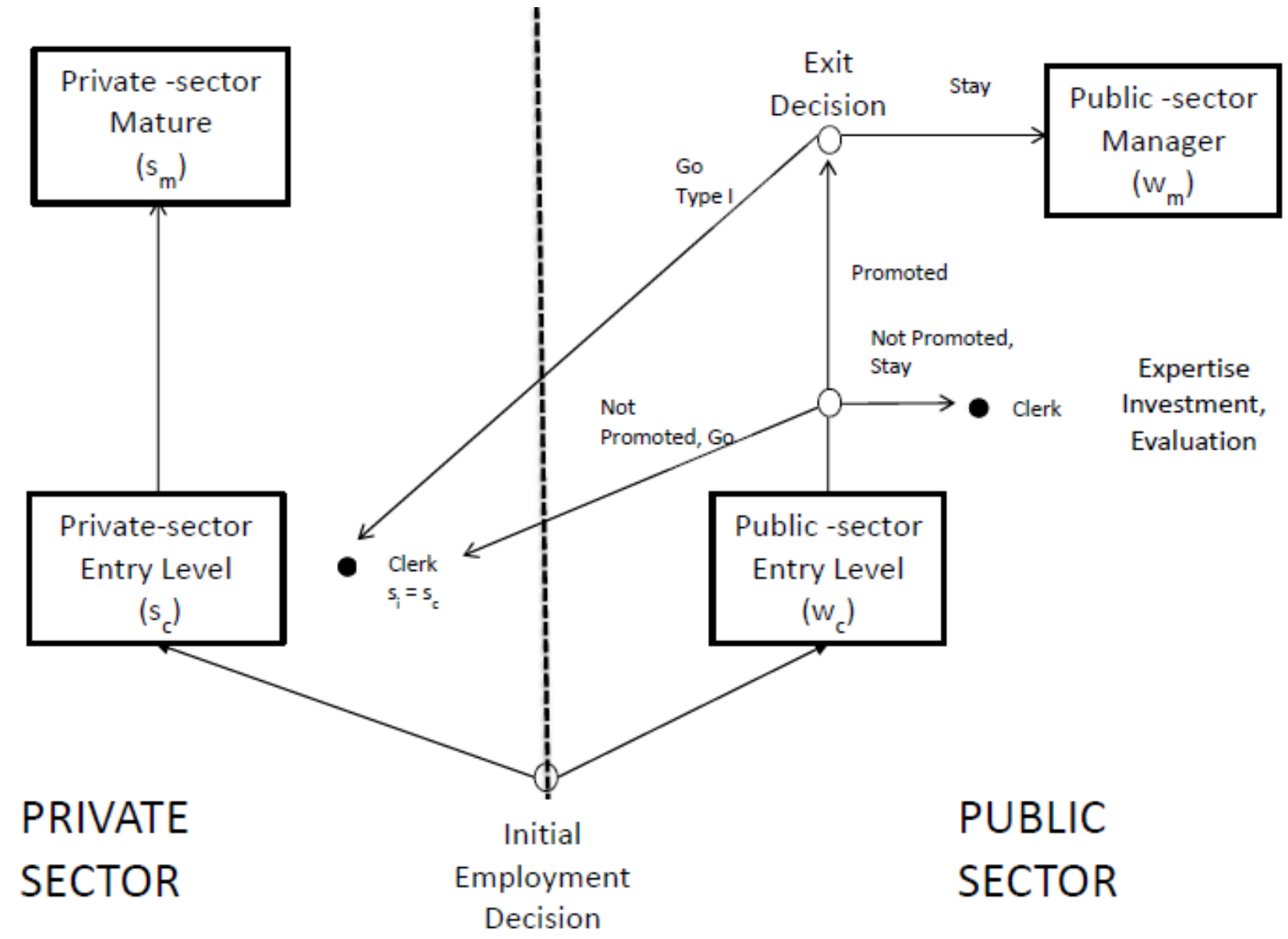

Figure 3: Career Paths in the Type I Environment 


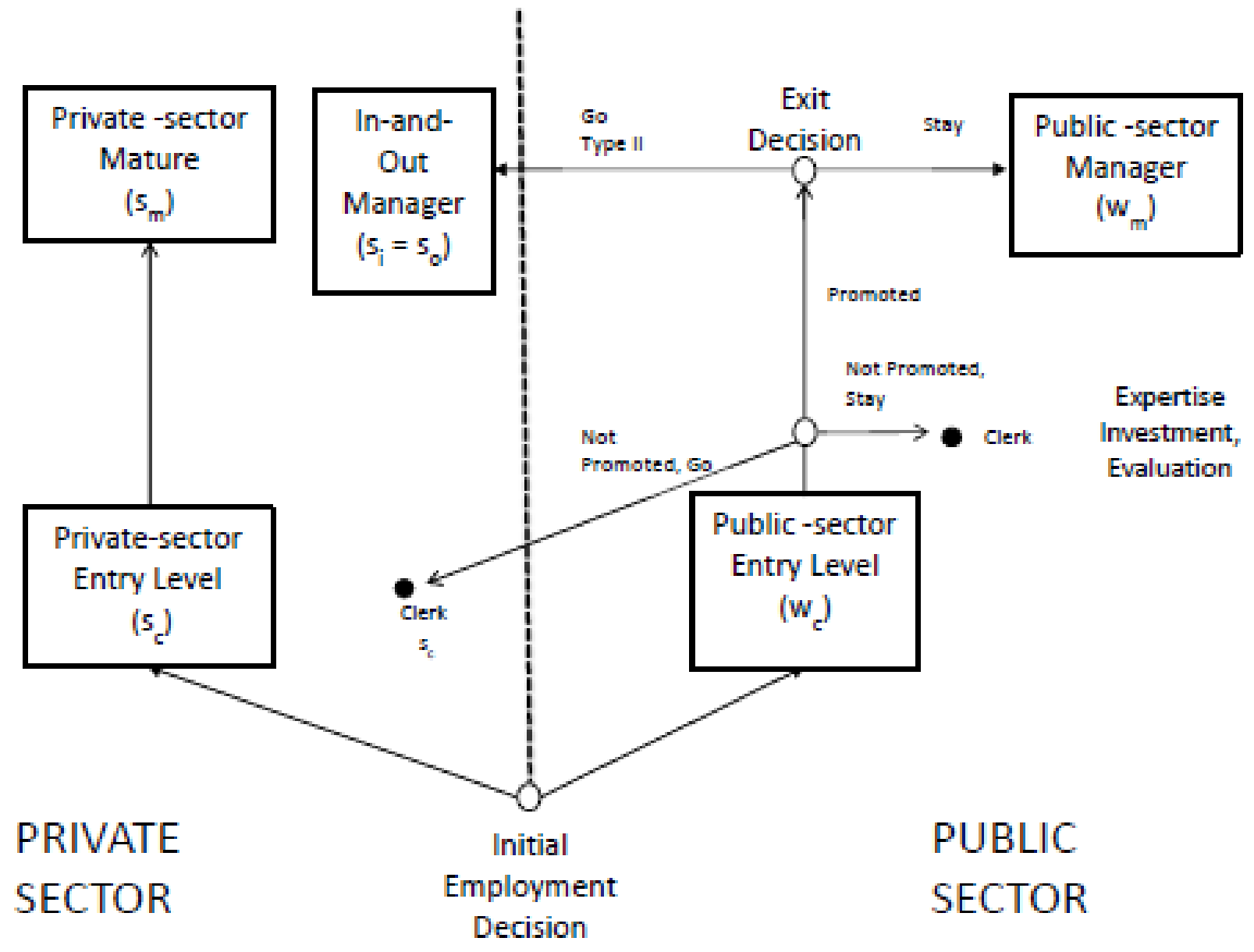

Figure 4: Career Paths in the Type II Environment

position in the private sector.

The critical feature of career paths in the Type II environment is that a promoted public sector manager can exit as an in-and-outer into a lucrative job in the private sector that abundantly rewards his investment in expertise.

\section{Equilibrium}

Although the construction of equilibria is somewhat involved, the following points may clarify the basic logic. With respect to policy-making, the Boss will adopt either a credulous or skeptical stance to the manager's recommendations, depending on whether there is low or high conflict between them. Politicization in the former case creates an Aghion-Tirole 
effect, that is, it undermines the manager's motivation to work hard. But in the latter case, politicization creates a reverse Aghion-Tirole effect, inducing greater motivation to work hard. Both politicization and the degree of interest convergence or conflict between the manager and Boss have powerful effects on the manager's job satisfaction, with profound implications for the operation of personnel policies.

With respect to personnel policies, in Type I agencies outside wages are unresponsive to expertise acquired in the agency. Consequently, the agency must set managerial wages to compensate an employee for her investment costs if she is to acquire expertise. Critically, zealots receive job satisfaction from occupying a policy-making billet, and this utility wedge between them and slackers allows the agency to set managerial wages that motivate zealots to seek promotion but fail to motivate slackers, hence expertise screening. Thus, in an expertise screening equilibrium, slackers do not invest in expertise and are not promoted while zealots do invest, are promoted, and remain in the agency.

In Type II agencies, outside wages are highly responsive to expertise acquired in the agency. The agency must respond to these outside opportunities as it sets managerial wages if it is to retain employees. But again, the utility wedge between zealots and slackers allows the agency to set wages that will motivate zealots to remain with the agency but will fail to do so for slackers; hence, managerial sorting. In a managerial sorting equilibrium, both slackers and zealots invest in expertise and are promoted, but slackers then leave the agency for greener pastures in the private sector. In contrast, zealots remain in the agency.

With respect to the Boss's design decisions, the following points may be helpful. For a given promotion standard and a given politicization level, the wage structure in the agency is tied down by the outside wages, the expertise screening and managerial sorting conditions, participation constraints for employees, and economizing behavior by the Boss. Consequently, for a contract impelling the desired behavior by the employee, the Boss sets the promotion standard and politicization levels, adjusting wages accordingly, so as to maximize her utility. 


\section{A. Policy-Making}

Manager Recommendations and Boss Decisions. -We begin by analyzing the play of the game after a manager (a promoted Subordinate) has undertaken his work effort $a$ (which may be zero). One of four states then prevails, and the manager knows which one: $\left(X_{H}, Y_{H}\right),\left(X_{H}, Y_{L}\right),\left(X_{L}, Y_{H}\right)$, and $\left(X_{L}, X_{L}\right)$. The Boss does not know which state exists. A recommendation strategy $r$ maps the type of the manager (slacker or zealot) and these four states into a positive or negative recommendation (that is, the manager recommends the project he has uncovered, if any, or he does not). The manager's objective is to set this recommendation strategy to maximize $\operatorname{\theta rdX}$ (see Equation 1).

Following a positive recommendation, with probability $\pi$ the Boss becomes informed and learns which state prevails. If he is informed, a decision strategy $d$ maps the four states into an accept/reject decision. If he is not informed, the Boss can condition his decision only on the facts that the manager passed the civil service exam and has now made a positive recommendation. Let $\sigma \in\left\{Y_{H}, Y_{L}, \varnothing\right\}$ (the Boss's information set) where $\varnothing$ connotes the uninformed state for the Boss.

Lemma 1. (Project Recommendations and Decisions). For the manager:

$$
r^{*}(X, Y ; \theta)=\left\{\begin{array}{c}
1 \text { (recommend) if } \theta=1 \text { (zealot) and } X=X_{H} \\
0 \text { (don't recommend) otherwise }
\end{array}\right.
$$

For the Boss: If $p \geq p^{*}$

$$
d^{*}(\sigma ; p)=\left\{\begin{array}{c}
0 \text { (reject) if informed and } \sigma=Y_{L} \\
1 \text { (accept) if } \sigma=Y_{H} \text { or } \varnothing
\end{array}\right.
$$

If $p<p^{*}$

$$
d^{*}(\sigma ; p)=\left\{\begin{array}{c}
1 \text { (accept) if informed and } \sigma=Y_{H} \\
0 \text { (reject) if } \sigma=Y_{L} \text { or } \varnothing
\end{array}\right.
$$


where $p^{*} \equiv-\frac{Y_{L}}{Y_{H}-Y_{L}}$.

Proof. See Appendix A.

The Lemma indicates that a zealot-type manager recommends only projects he favors, and always does so. The Boss's acceptance strategy varies radically between the low conflict environment $\left(p \geq p^{*}\right)$ and the high conflict environment $\left(p<p^{*}\right)$. In the low conflict environment, the Boss always accepts the manager's recommendation unless the Boss receives independent adverse information from his own centralized review. Hence, this is a credulous acceptance strategy. In the high conflict environment, the Boss always rejects the manager's recommendation unless the Boss receives independent favorable information from his own centralized review. So, if his independent review reveals nothing, the Boss rejects the manager's "pig in the poke." This is a skeptical acceptance strategy.

Manager's Policy-making Effort. - In deciding on a level of work $a$, the manager takes as given the level of politicization $\pi$ and the cost-of-effort parameter $\gamma=1 / e$. From his perspective, the ex ante probability of each $(X, Y)$ state is:

$$
\begin{aligned}
& \operatorname{Pr}\left(X_{H}, Y_{H}\right)=a p \\
& \operatorname{Pr}\left(X_{H}, Y_{L}\right)=a(1-p) \\
& \operatorname{Pr}\left(X_{L}, Y_{H}\right)=(1-a) q \\
& \operatorname{Pr}\left(X_{L}, Y_{L}\right)=(1-a)(1-q)
\end{aligned}
$$

Given the strategies in Lemma 1 , if $p \geq p^{*}$ the manager seeks to maximize

$$
\begin{aligned}
& w_{m}+\theta\left[\pi\left(a p X_{H}\right)+(1-\pi)(a p+a(1-p)) X_{H}\right]-\gamma a^{2} \\
= & w_{m}+\theta a(1-(1-p) \pi) X_{H}-\gamma a^{2}
\end{aligned}
$$


However, if $p<p^{*}$ the manager seeks to maximize

$$
w_{m}+\theta\left[\pi\left(a p X_{H}\right)+(1-\pi) 0\right]-\gamma a^{2}
$$

Lemma 2. (Policy-making Effort) For a promoted Subordinate optimal policy-making effort is:

$$
a^{*}(\pi, \gamma ; \theta)=\left\{\begin{array}{c}
\theta\left(\frac{(1-(1-p) \pi) X_{H}}{2 \gamma}\right) \text { if } p \geq p^{*} \\
\theta\left(\frac{p \pi X_{H}}{2 \gamma}\right) \text { if } p<p^{*}
\end{array}\right.
$$

where $p^{*} \equiv-\frac{Y_{L}}{Y_{H}-Y_{L}}$.

Proof. i) A slacker $(\theta=0)$ clearly undertakes no policy effort as it brings no utility gain and an effort loss. ii) For a zealot $(\theta=1)$, the indicated results follow immediately from the first order condition for the manager's optimization programs Equation 2 and Equation 3. Comment: A corner solution $a^{*}=1$ is possible. Using Lemma 4 and Equation 6, one can verify that as long as the following conditions hold, $a^{*}$ is an interior solution even when $\gamma$ is determined endogenously by $e^{*}: \bar{e} X_{H} \leq 2$ and $X_{H}^{3} \leq 16 \kappa$. QED

Note that a slacker undertakes no effort, while a zealot undertakes positive effort for any level of politicization in both regimes (except $\pi=0$ in the high conflict environment).

In Section V, we consider the general equilibrium effects of policy conflict. But it is worth noting the partial equilibrium effects of an increase in politicization, $\pi$, on work effort $a$. From inspection of Equation 4, in the low conflict environment $\left(p \geq p^{*}\right)$ the manager works less as politicization increases. This is an example of the well-known Aghion-Tirole effect in which meddling by the Boss reduces work effort by the agent (Aghion and Tirole 1997). However, the situation is quite different in the high conflict environment $\left(p<p^{*}\right)$. There, increased politicization brings greater effort by the manager, a reverse Aghion-Tirole effect. 
The explanation is simple. In the high conflict environment, the Boss employs a skeptical acceptance strategy, in which he rejects all recommendations unless he receives corroboration that the recommended project is a good one $\left(Y=Y_{H}\right)$. Consequently, politicization (the probability of independent corroboration) increases the marginal return to the manager from policy work.

\section{B. The Internal Labor Market}

We now turn to the decision of subordinates to join the agency, the decision to remain employed there rather than exit for the private sector, the agency's promotion decision, and subordinates' acquisition of human capital.

The Exit or Stay Decision Following the Promotion Evaluation.-After the promotion evaluation, the Subordinate must decide whether to stay in the agency or leave for the private sector (reference to Figures 2 and 3 may be helpful). There are four potential classes of employees: a promoted zealot, a non-promoted zealot, a promoted slacker, and a non-promoted slacker. That is, a zealot-type manager, a zealot-type clerk, a slacker-type manager, and a slacker-type clerk. ${ }^{9}$ Each compares the expected value of remaining in the agency, with exiting and receiving the outside wage. For a newly promoted manager, the outside wage is $s_{i}$ (whose value is either $s_{c}$ in a Type I agency or $s_{o}=s_{c}+\kappa e^{2}$ in a Type II agency). For a non-promoted clerk, the outside wage is $s_{c}$.

The expected utility of staying is easily calculated. First consider a zealot-type manager $(\theta=1)$. Substituting Equation 4 into Equations 2 and 3, yields the expected utility of staying

$$
E u_{2}^{s} \mid(\operatorname{stay}, \theta=1)=\left\{\begin{array}{c}
w_{m}+\frac{(1-(1-p) \pi)^{2}}{4 \gamma}\left(X_{H}\right)^{2} \text { if } p \geq p^{*} \\
w_{m}+\frac{p^{2} \pi^{2}}{4 \gamma}\left(X_{H}\right)^{2} \text { if } p<p^{*}
\end{array}\right.
$$


It proves convenient to define:

$$
\beta\left(\pi ; p, X_{H}\right)=\left\{\begin{array}{c}
\beta_{1}=\frac{(1-(1-p) \pi)^{2}}{4}\left(X_{H}\right)^{2} \text { if } p \geq p^{*} \\
\beta_{2}=\frac{(p \pi)^{2}}{4}\left(X_{H}\right)^{2} \text { if } p<p^{*}
\end{array}\right.
$$

So Equation 5 becomes

$$
E u_{2}^{s} \mid(\operatorname{stay}, \theta=1)=w_{m}+\frac{\beta}{\gamma}=w_{m}+\beta e
$$

The term $\frac{\beta}{\gamma}$ indicates the non-wage job satisfaction (intrinsic motivation) received by a zealot who holds a policy-making position. Note that $\frac{\beta}{\gamma}$ must be non-negative.

Now consider a slacker-type manager $(\theta=0)$. Such a subordinate does not value policy (moreover, via Lemma 2 he undertakes no policy work and consequently would not find an $X_{H}$ project in any case). Given this, his expected utility from staying is simply his wage $w_{m}$. Similarly, a passed-over slacker-type clerk will not undertake any investment in expertise since there is no opportunity for promotion. Hence, his expected utility is simply his wage $w_{c}$. Finally, consider a zealot-type clerk. Because he was not promoted, the manager job remains unfilled so no manager recommends a project. Hence the expected policy value of agency action is zero. And without the prospect of promotion, the passed-over zealot-type clerk will not invest in human capital. Hence, his expected utility in the second period is also simply the wage $w_{c}$. Thus we have:

$$
E u_{2}^{s} \mid(\text { stay })=\left\{\begin{array}{c}
w_{m}+\theta \frac{\beta_{1}}{\gamma} \text { if promoted and } p \geq p^{*} \\
w_{m}+\theta \frac{\beta_{2}}{\gamma} \text { if promoted and } p<p^{*} \\
w_{c} \text { if not promoted }
\end{array}\right.
$$

Lemma 3. (Exit or Stay Decision after Promotion Evaluation) a) If $p \geq p^{*}$ (low conflict environment) a zealot-type manager will remain with the agency if and only if $\frac{\beta_{1}}{\gamma} \geq s_{i}-w_{m}$; b) If $p<p^{*}$ (high conflict environment) a zealot-type manager will remain with the agency 


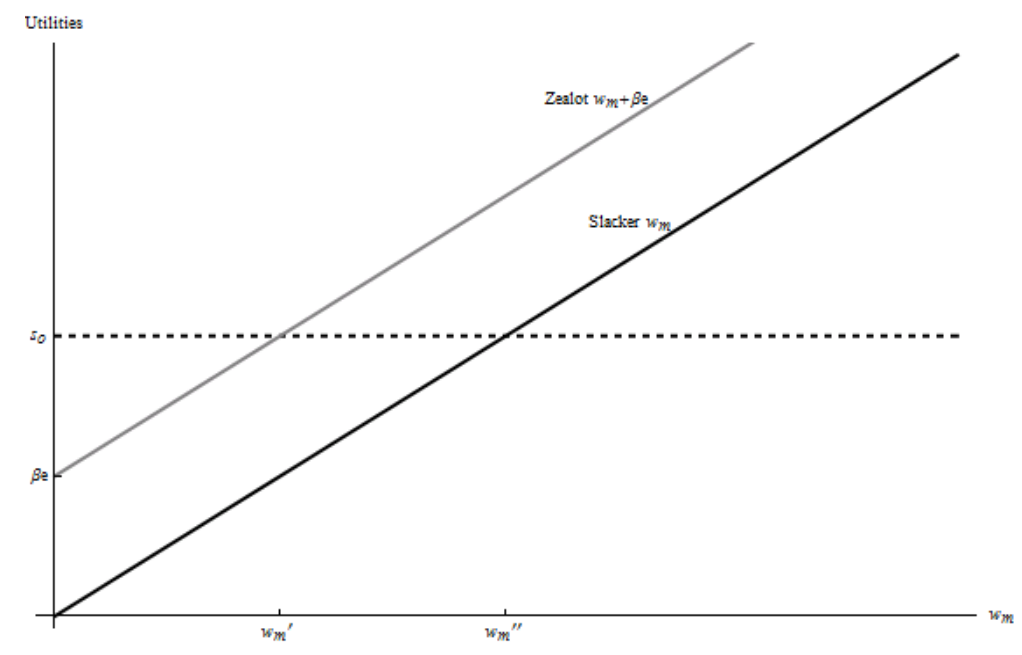

Figure 5: The post-promotion decision to stay or go (Type II agencies).

if and only if $\frac{\beta_{2}}{\gamma} \geq s_{i}-w_{m}$; c) A slacker-type manager will exit the agency if and only if $s_{i} \geq w_{m}$; c) Non-promoted subordinates will remain with the agency if and only if $w_{c} \geq s_{c}$.

Proof. Follows from comparison of the expected utilities in Equation 7 with the outside wages for clerks and managers ( $s_{c}$ and $s_{i}$, respectively). QED

An implication of the Lemma is that managerial sorting will occur if

$$
w_{m}<s_{i} \leq w_{m}+\frac{\beta(\pi ; p)}{\gamma}
$$

If this managerial sorting condition holds, promoted zealots will stay in the agency but promoted slackers will exit. Conversely, if the post-promotion outside wage $s_{i}<w_{m}$ sorting cannot work since both slackers and zealots, if promoted, will remain with the agency. The managerial sorting condition will also fail if $w_{m}+\frac{\beta}{\gamma}<s_{i}$, since then both slackers and zealots will leave the agency for the private sector. Note that in a Type II agency, where $s_{i}=s_{o}=s_{c}+\kappa e$, the minimum wage that induces managerial sorting is $w_{m}=s_{c}+\kappa \bar{e}-\beta e$. Retention of non-promoted subordinates requires that the agency pay clerks at least as well as the private sector $w_{c} \geq s_{c}$.

Figure 5 provides some intuition about managerial sorting in Type II agencies. As 
shown, the outside wage is $s_{o}$, the horizontal dashed line in the figure, which is the utility of employment in the private sector for both the slacker and the zealot. If a promoted zealot remains in the agency her utility, $w_{m}+\beta e$, increases in the agency's managerial wage $w_{m}$. If $w_{m}$ is less than $w_{m}^{\prime}$, the utility from private-sector employment is greater than that from public-sector employment so the zealot leaves the agency. But, for higher $w_{m}$, she remains. A similar calculation holds for the slacker, but the switch-over wage is $w_{m}^{\prime \prime}$. Critically, $w_{m}^{\prime}<w_{m}^{\prime \prime}$, so that wages in the interval $\left[w_{m}^{\prime}, w_{m}^{\prime \prime}\right)$ will induce the zealot to remain with the agency but the slacker to exit for the private sector. Straightforwardly, $w_{m}^{\prime}=s_{o}-\beta e$.

Expertise Acquisition and Promotion. - In order to be promoted, a clerk must acquire expertise at least as great as the promotion standard $\bar{e}$. How much expertise to acquire depends on the agency's wage structure, promotion standard, and politicization of decision-making, as well as on the outside wage opportunity after promotion.

It is straight-forward to find the optimal level of investment, given a contract $\left(w_{c}, w_{m}, \bar{e}\right)$, outside wages, a level of politicization $\pi$ and degree of conflict $p$. In doing so, several facts are useful. First, in both a Type I and Type II agency, prior to investment the expected value to a zealot of investing, being promoted, and remaining in the agency is $w_{m}+\beta(p) e-k e^{2}$ while that of a slacker is $w_{m}-k e^{2}$.Second, in a Type II agency if a promoted manager departs for the private sector her outside wage will be set assuming $e=\bar{e}$. This follows from the assumption that the private employer can only observe the fact of promotion, not the employee's actual evaluation or investment. Hence, prior to investment, in a Type II agency the expected value of investing, being promoted, and departing is $s_{o}(\bar{e})-k \bar{e}$ for both a slacker andr zealot.

Lemma 4. Strategies for Investment in expertise are: 1) In a Type I agency

$$
e^{*}(\theta=0)=\left\{\begin{array}{c}
\bar{e} \text { if } w_{m}-k \bar{e}^{2} \geq \max \left\{s_{c}, w_{c}\right\} \\
0 \text { otherwise }
\end{array}\right.
$$




$$
e^{*}(\theta=1)=\left\{\begin{array}{c}
\bar{e} \text { if } w_{m}+\beta \bar{e}-k \bar{e}^{2} \geq \max \left\{s_{c}, w_{c}\right\} \text { and } \bar{e} \geq \frac{\beta}{2 k} \\
\frac{\beta}{2 k} \text { if } w_{m}+\frac{1}{4} \frac{\beta^{2}}{k} \geq \max \left\{s_{c}, w_{c}\right\} \text { and } \bar{e}<\frac{\beta}{2 k} \\
0 \text { otherwise }
\end{array}\right.
$$

2) In a Type II agency

$$
\begin{aligned}
& e^{*}(\theta=0)=\left\{\begin{array}{c}
\bar{e} \text { if } \max \left\{w_{m}, s_{o}\right\}-k \bar{e}^{2} \geq \max \left\{s_{c}, w_{c}\right\} \\
0 \text { otherwise }
\end{array}\right. \\
& e^{*}(\theta=1)=\left\{\begin{array}{c}
\bar{e} \text { if }\left\{\begin{array}{c}
\max \left\{w_{m}+\beta \bar{e}, s_{o}\right\}-k \bar{e}^{2} \geq \max \left\{s_{c}, w_{c}\right\} \text { and } \bar{e} \geq \frac{\beta}{2 k} \\
s_{o}-k \bar{e}^{2}>w_{m}+\frac{1}{4} \frac{\beta^{2}}{k}, \max \left\{s_{c}, w_{c}\right\} \text { and } \bar{e}<\frac{\beta}{2 k}
\end{array}\right. \\
\frac{\beta}{2 k} \text { if } w_{m}+\frac{1}{4} \frac{\beta^{2}}{k} \geq s_{o}-k \bar{e}^{2}, \max \left\{s_{c}, w_{c}\right\} \text { and } \bar{e}<\frac{\beta}{2 k} \\
0 \text { otherwise }
\end{array}\right.
\end{aligned}
$$

Proof. See Appendix A.

The lemma has an important implication in Type I agencies: If a Type I agency sets managerial wages properly, only zealots will invest. The following Corollary indicates this "promotion screening" wage.

Corollary 5. In a Type I agency if

$$
\left.\begin{array}{c}
\max \left\{w_{c}, s_{c}\right\}+k \bar{e}^{2}-\beta \bar{e} \text { if } \bar{e} \geq \frac{\beta}{2 k} \\
\max \left\{w_{c}, s_{c}\right\}-\frac{1}{4} \frac{\beta^{2}}{k} \text { if } \bar{e}<\frac{\beta}{2 k}
\end{array}\right\} \leq w_{m}<\max \left\{w_{c}, s_{c}\right\}+k \bar{e}^{2}
$$

then zealots acquire expertise and are promoted and remain in the agency while slackers do not acquire expertise and are not promoted.

Proof. Using the Lemma, if a slacker is not to invest in expertise In a Type I agency it must the case that $w_{m}-k \bar{e}^{2}<\max \left\{s_{c}, w_{c}\right\}$. Conversely, if a zealot is to invest in expertise and remain with the agency it must be the case that $w_{m}+\beta \bar{e}-k \bar{e}^{2} \geq \max \left\{s_{c}, w_{c}\right\}$ when $\bar{e} \geq \frac{\beta}{2 k}$, 


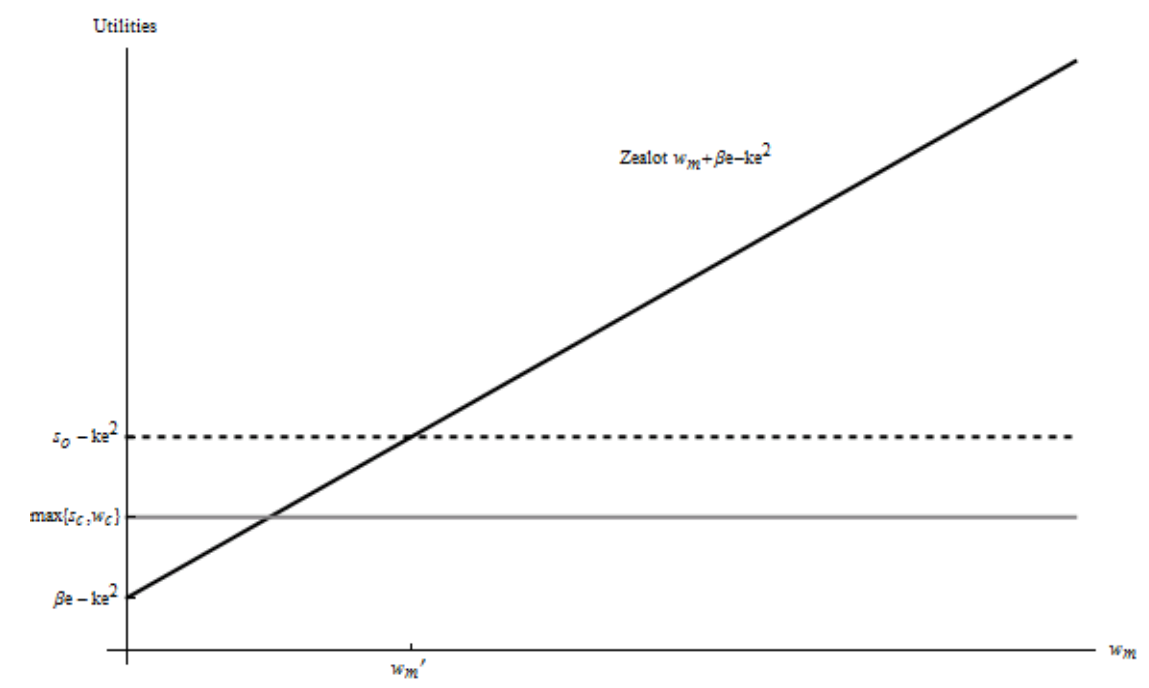

Figure 6: The Investment Decision in Type II Agencies

and $w_{m}+\frac{1}{4} \frac{\beta^{2}}{k} \geq \max \left\{s_{c}, w_{c}\right\}$ when $\bar{e}<\frac{\beta}{2 k}$. Equation 9 simply re-states these conditions. QED

Equation 9 indicates a set of managerial wages that will induce a zealot in a Type I agency to invest in expertise up to or beyond the promotion standard and then remain in the agency, but will not do so for the slacker. Equation 9 thus provides the promotion screening condition for Type I agencies. If this condition holds, zealots will invest in expertise and be promoted but slackers will not. The condition exploits the fact that zealots receive job satisfaction from the policy making job while slackers to not. Hence, one can pay a wage that compensates zealots for their efforts, but will not compensate slackers for theirs.

Figure 6 provides some intuition about investment decisions in Type II agencies. A slacker compares the wage from investment, promotion and exit $\left(s_{0}-k \bar{e}^{2}\right.$, the horizontal dashed line in the figure) with the wage from not investing $\left(\max \left\{s_{c}, s_{m}\right\}\right.$, the gray horizontal line in the figure). If $s_{0}-k \bar{e}^{2} \geq \max \left\{s_{c}, s_{m}\right\}$ (so the dashed line is above the horizontal line in the figure), this option is attractive. But the slacker must also compare the expected utility of investing and exiting with the utility from investing and staying, that is, $s_{0}-k \bar{e}^{2}$ with $w_{m}-k \bar{e}^{2}$. The slacker will invest, be promoted, and exit if $w_{m}<w_{m}{ }^{\prime}=s_{0}$. The wage $w_{m}{ }^{\prime}$ is not shown in the figure, but note that it is the same wage shown in Figure 5. The zealot's 
Table 2: EU of Slacker-type Upon Joining the Agency

\begin{tabular}{ccc}
\hline \hline & Stay & Exit \\
\hline Invest & $w_{c}+w_{m}-k \bar{e}^{2}$ & $w_{c}+s_{i}-k \bar{e}^{2}$ \\
Don't Invest & $2 w_{c}$ & $w_{c}+s_{c}$ \\
\hline \hline
\end{tabular}

Table 3: EU of Zealot-type Upon Joining the Agency

\begin{tabular}{ccc}
\hline \hline & Stay & Exit \\
\hline Invest & $w_{c}+w_{m}+\beta \bar{e}-k \bar{e}^{2}$ & $w_{c}+s_{i}-k \bar{e}^{2}$ \\
Don't Invest & $2 w_{c}$ & $w_{c}+s_{c}$ \\
\hline \hline
\end{tabular}

expected utility from investing, being promoted, and remaining in the agency is shown by the upward sloping line in Figure 6. If $w_{m}<w_{m}{ }^{\prime}$ the zealot will invest, be promoted, and exit the agency. If $w_{m} \geq w_{m}{ }^{\prime}$ the zealot will invest, be promoted, and remain in the agency. Note that this wage is again exactly that shown in Figure 5.

Initial Employment Decision. - A potential employee compares his expected utility from employment in the government agency, with his expected utility from employment in the private sector. If he is to accept employment with the agency, the return from the ensuing public career must be at least as good as that from a private sector career. ${ }^{10}$ The expected utility of a private sector career is $s_{c}+s_{m}$ Hence, it must be the case that a public career yields at payoff of at least $s_{c}+s_{m}$. (Recall that $s_{m}$ is the expected net payoff in the second period in the private sector, which reflects promotion probabilities, cost of human capital investment in the private sector, and so on).

The expected utility of a public career depends on whether the employee invests in human capital and receives promotion, or doesn't invest and isn't promoted (as indicated by Lemma 4), and whether the employee exits or remains in the agency after the promotion/no promotion event (as indicated by Lemma 3). There are thus four possible public sector careers, each with a specific utility. These possible careers and associated utilities are shown in Tables 2 and 3, the first table for slackers, the second for zealots. In any equilibrium in which one of these eight careers occurs, the payoff from that career must yield at least $s_{c}+s_{m}$ if the potential employee is to enter the public sector. 
We now consider the implications of this fact in two candidate equilibria. In a promotion screening equilibrium, we conjecture that slackers do not invest in expertise to the promotion standard and are not promoted, but remain with the agency. In contrast, zealots do invest, are promoted, and remain with the agency. In a managerial sorting equilibrium, both slackers and zealots invest and are promoted. But then, the slackers exit while the zealots remain.

Lemma 6. 1. In the conjectured promotion screening equilibrium, a) $w_{c} \geq \frac{s_{c}+s_{m}}{2}$ and b) if the entry wage is set so slackers are indifferent between a public and private career, then $w_{m}+\beta \bar{e}-k \bar{e}^{2} \geq w_{c}$. 2. In the conjectured managerial sorting equilibrium, if employees are indifferent between a public and private career then a) $w_{m}+\beta \bar{e}=s_{i}$ and b) if $s_{i}-k \bar{e}^{2}$ rises (falls) in $\bar{e}$ than $w_{c}$ must fall (rise) in $\bar{e}$.

Proof. See Appendi A.

\section{Agency Design}

We now turn to the Boss's design of the agency. We examine Type I and Type II agencies separately, though the two analyses parallel one another closely. Broadly speaking, in Type I agencies a contract that induces promotion screening is very attractive to the Boss. This contract is not feasible in Type II agencies, so a contract that induces managerial sorting becomes very attractive. In both cases, the need to efficiently induce screening or sorting ties down the managerial wage function, given levels of politicization and a promotion standard. Given this, the Boss sets the politicization level and promotion standard to maximize his utility, taking into account the effects on policy-making.

Type I Agencies. - In the first period, the Boss receives a payoff $v-w_{c}$ (conditional on an employee accepting employment in the agency). Table 4 indicates the payoffs to the Boss in the second period from possible second period careers of a slacker and zealot (the first payoff in the parenthesis occurs when the employee is a slacker, the second if he is a zealot, and $E Y$ indicates the expected policy payoff from a zealot's work efforts). Without a formal proof, we assert that the best payoff for the Boss comes from a contract inducing 


\begin{tabular}{|l|l|l|l|}
\hline & \multicolumn{3}{|c|}{ Zealot } \\
\hline Slacker & Public Manager & Public Clerk & Private Clerk \\
\hline Public manager & $\left(-w_{m}, E Y-w_{m}\right)$ & $\left(-w_{m}, v-w_{c}\right)$ & $\left(-w_{m}, 0\right)$ \\
Public clerk & $\left(v-w_{c}, E Y-w_{m}\right)$ & $\left(v-w_{c}, v-w_{c}\right)$ & $\left(v-w_{c}, 0\right)$ \\
Private clerk & $\left(0, E Y-w_{m}\right)$ & $\left(0, v-w_{c}\right)$ & $(0,0)$ \\
\hline
\end{tabular}

Table 4: The Boss's Second Period Payoffs from the Second Period Careers (Type I Agency)

a slacker to remain a public clerk, but inducing a zealot to become a public sector manager and remain in the agency. (Note that screening avoids paying slackers to invest in expertise, a pointless endeavor since they will not engage in policy work if promoted. Moreover, the least cost screening wage is actually lower than the least-cost non-screening wage (that is, one that induces slackers to invest as well as zealots)).

We now derive the Boss's expected utility in the design variables. In a screening equilibrium in a Type I agency, if the employee is a zealot then the Boss's expected utility in the second period is, if $p \geq p^{*}$

$$
\begin{aligned}
E u_{2}^{B} \mid(\theta & =1)=E Y-w_{m} \\
& =\pi\left(a^{*} p Y_{H}\right)+(1-\pi)\left(a^{*} p Y_{H}+a^{*}(1-p) Y_{L}\right)-w_{m} \\
& =a^{*}\left(p Y_{H}+(1-\pi)(1-p) Y_{L}\right)-w_{m}
\end{aligned}
$$

If $p<p^{*}$ then it is

$$
\begin{aligned}
E u_{2}^{B} \mid(\theta & =1)=E Y-w_{m} \\
& =\pi\left(a^{*} p Y_{H}\right)+(1-\pi)(0)-w_{m}
\end{aligned}
$$

so that

$$
E u_{2}^{B} \mid(\theta=1)=\left\{\begin{array}{c}
a^{*}\left(p Y_{H}+(1-\pi)(1-p) Y_{L}\right)-w_{m} \text { if } p \geq p^{*} \\
\pi\left(a^{*} p Y_{H}\right)-w_{m} \text { if } p<p^{*}
\end{array}\right.
$$


Let $\lambda$ denote the proportion of zealots in the employment pool. Then the Boss's expected utility at the design stage is just the first period utility plus the expected second period utility:

$$
\begin{aligned}
E u^{B} & =v-w_{c}+(1-\lambda)\left(v-w_{c}\right)+\lambda\left(E u_{2}^{B} \mid(\theta=1)\right) \\
& =(2-\lambda)\left(v-w_{c}\right)+\lambda\left(E u_{2}^{B} \mid(\theta=1)\right)
\end{aligned}
$$

Clearly the values of $\pi$ and $\bar{e}$ that maximize $E u_{2}^{B}$ also maximize $E u_{2}^{B} \mid(\theta=1)$ (provided $w_{c}$ is not affected by the values of those variables, a point we return to below). Returning then to Equation 10, recall the definition of $a^{*}$ from Lemma 2 (Equation 4), recall that $\gamma=1 / e$, and recall the definition of $\beta$ (Equation 6). Further (recall that the least-cost promotion screening wage is $w_{m}=w_{c}+k \bar{e}^{2}-\beta \bar{e}$. Combining these with the definition of the least-cost screening wage yields:

$$
E u_{2}^{B} \mid \theta=1=
$$

$$
\left\{\begin{array}{l}
\left(\frac{1-(1-p) \pi}{2} X_{H} \bar{e}\right)\left(p Y_{H}+(1-\pi)(1-p) Y_{L}\right)-k \bar{e}^{2}+\left(\frac{(1-(1-p) \pi)^{2}\left(X_{h}\right)^{2}}{4}\right) \bar{e}-w_{c} \text { if } p \geq p^{*} \\
\left(\frac{p^{2} \pi^{2}\left(X_{H}+2 Y_{H}\right)}{4}\right) \bar{e}-k \bar{e}^{2}-w_{c} \text { if } p<p^{*}
\end{array}\right.
$$

Optimal values of $\pi$ and $\bar{e}$ may now be found straightforwardly and are indicated in the following lemma.

Lemma 7. In a Type I agency the optimal level of politicization and optimal promotion standard are:

$$
\pi^{*}\left(p, Y_{H}, Y_{L}, X_{H}\right)=\left\{\begin{array}{c}
1 \text { if } p<p^{*} \\
\frac{X_{H}+2 Y_{L}+p\left(Y_{H}-Y_{L}\right)}{(1-p)\left(X_{H}+2 Y_{L}\right)} \text { if } p^{*} \leq p \leq p^{* *} \\
0 \text { if } p>p^{* *}
\end{array}\right.
$$




$$
\bar{e}^{*}\left(p, Y_{H}, Y_{L}, X_{H}, k\right)=\left\{\begin{array}{c}
\frac{p^{2} X_{H}\left(X_{H}+2 Y_{H}\right)}{8 k} \text { if } p<p^{*} \\
-\frac{p^{2} X_{H}\left(Y_{H}-Y_{L}\right)^{2}}{\left(X_{H}+2 Y_{L}\right) 8 k} \text { if } p^{*} \leq p \leq p^{* *} \\
\frac{X_{H}\left(X_{H}+2\left(p\left(Y_{H}-Y_{L}\right)+Y_{L}\right)\right)}{8 k} \text { if } p>p^{* *}
\end{array}\right.
$$

where $p^{*}=-\frac{Y_{L}}{Y_{H}-Y_{L}}$ and $p^{* *} \equiv-\frac{X_{H}+2 Y_{L}}{Y_{H}-Y_{L}}$.

Proof. See Appendix.

The lemma introduces a new condition, $p^{* *} \equiv-\frac{X_{H}+2 Y_{L}}{Y_{H}-Y_{L}}$. At this level of interest convergence, the optimal level of politicization goes to zero.

Now consider the entry level wage, $w_{c}$. Recall $s_{m}$, the net expected payoff in the second period from pursuing a private sector career. This value reflects promotion probabilities, the effort costs of investment in human capital, and so on.

Lemma 8. (Type I Agency Entry Level Wage) In a Type I agency where $\pi^{*}$ and $\bar{e}^{*}$ are set according to Lemma 7 , then $w_{c}=\frac{s_{c}+s_{m}}{2}$ assures both slackers and zealots accept initial employment with the agency.

Proof. Slackers employed in the agency do not seek promotion and thus receive $2 w_{c}$. The relevant participation constraint is thus $2 w_{c} \geq s_{c}+s_{m}$ and the least-cost entry wage satisfying this $w_{c}=\frac{s_{s}+s_{m}}{2}$. For zealots, the equilibrium is constructed so that a zealot employed by the agency is just indifferent between investing in expertise and being promoted, and not investing. Hence the same participation constraint applies. QED

If the average private sector wage profile is increasing, the lemma implies that entrylevel wages in the public sector will be somewhat higher than entry-level wages in the private sector

We can now combine results to indicate the promotion screening equilibrium in Type I agencies.

Proposition 9. In a Type I agency the following is an equilibrium. The Boss offers the contract $\left(w_{c}, w_{m}, \bar{e}^{*}\right)$ and then chooses a level of politicization $\pi^{*}$, where $w_{c}=\frac{s_{c}+s_{m}}{2}, w_{m}=$ 


\begin{tabular}{|l|l|l|l|l|}
\hline & \multicolumn{4}{|c|}{ Zealot } \\
\hline Slacker & Public Manager & Private Manager & Public Clerk & Private Clerk \\
\hline Public manager & $\left(-w_{m}, E Y-w_{m}\right)$ & $\left(-w_{m}, 0\right)$ & $\left(-w_{m}, v-w_{c}\right)$ & $\left(-w_{m}, 0\right)$ \\
Private manager & $\left(0, E Y-w_{m}\right)$ & $(0,0)$ & $\left(0, v-w_{c}\right)$ & $(0,0)$ \\
Public clerk & $\left(v-w_{c}, E Y-w_{m}\right)$ & $\left(v-w_{c}, 0\right)$ & $\left(v-w_{c}, v-w_{c}\right)$ & $\left(v-w_{c}, 0\right)$ \\
Private clerk & $\left(0, E Y-w_{m}\right)$ & $(0,0)$ & $\left(0, v-w_{c}\right)$ & $(0,0)$ \\
\hline
\end{tabular}

Table 5: The Boss's Second Period Payoffs from Second Period Careesr (Type II Agency) $k \bar{e}^{2}-\beta(p) \bar{e}+w_{c}$ and $\bar{e}^{*}$ and $\pi^{*}$ are defined in Lemma 8. Both slackers and zealots accept the contract; zealots invest in expertise level $\bar{e}^{*}$ and are promoted while stackers do not invest and are not promoted. Zealots then undertake policy making effort $a^{*}$ defined in Lemma 2 and recommend a project if and only if they discover $X>0$. If central review reveals $Y>0$ the Boss accepts the project. Otherwise he accepts the recommendation if and only if $p \geq p^{*}$.

Proof. Follows from above Lemmata. QED

Type II Agencies. - In a Type II agency, where the post-promotion outside wage $s_{i}$ is highly responsive to demonstrated expertise, the managerial wage must track the available outside wage after promotion, otherwise promoted employees will exit for the private sector. And, it is highly desirable to set the managerial wage to induce sorting, so that both slackers and zealots acquire expertise and are promoted but only zealots choose to remain with agency. Sorting avoids paying the managerial wage to slackers who will not engage in policy work if promoted. Moreover, the least-cost sorting wage is actually lower than the least-cost non-sorting age (that is, one that induces slackers to remain in the agency as well as zealots). Examination of Equation 8 indicates that the least-cost sorting wage is

$$
w_{m}=s_{i}-\beta(p) \bar{e}=w_{c}+\kappa \bar{e}^{2}-\beta(p) \bar{e}
$$

Recall from Lemma 7 that if $s_{i}-k \bar{e}^{2}$ varies in $\bar{e}$ then $w_{c}$ must adjust. The required relation is that $w_{c} \geq s_{c}+s_{m}-s_{i}+k \bar{e}^{2}$ and the least-cost entry wage is then

$$
w_{c}=\frac{s_{c}+s_{m}-\bar{e}^{2}(\kappa-k)}{2}
$$


As we assume $\kappa \geq k$, entry wages fall in the promotion standard $\bar{e}$.

The Boss's expected second period utility, given a promoted zealot, remains that shown in Equation 10:

$$
E u_{2}^{B} \mid \theta=1=\left\{\begin{array}{c}
a^{*}\left(p Y_{H}+(1-\pi)(1-p) Y_{L}\right)-w_{m} \text { if } p \geq p^{*} \\
\pi\left(a^{*} p Y_{H}\right)-w_{m} \text { if } p<p^{*}
\end{array}\right.
$$

However, the Boss's expected utility at the design stage is now:

$$
\begin{aligned}
E u^{B} & =v-w_{c}+(1-\lambda)(0)+\lambda\left(E u_{2}^{B} \mid \theta=1\right) \\
& =v-w_{c}+\lambda\left(E u_{2}^{B} \mid \theta=1\right)
\end{aligned}
$$

Employing the definitions for $w_{c}, a^{*}, w_{m}$, and $\beta(p)$ yields the following maximand when $p \geq p^{*}$

$$
\begin{aligned}
& \frac{1}{2}\left[\bar{e}^{2}(\kappa-k)-s_{c}-s_{m}\right]+v+\frac{1}{4} \lambda\left[-4 \kappa \bar{e}^{2}-2\left(\bar{e}^{2}(k-\kappa)+s_{c}+s_{m}\right)+\right. \\
& \left.2 \bar{e} X_{H}\left(p Y_{H}+(1-p)(1-\pi) Y_{L}\right)(1-(1-p) \pi)+\bar{e} X_{H}^{2}(1-(1-p) \pi)^{2}\right]
\end{aligned}
$$

However, when $p<p^{*}$ the Boss's maximand is

$$
v+\frac{1}{4}\left[-2\left(\bar{e}(k-\kappa)+s_{c}+s_{m}\right)(1+\lambda)+\bar{e} \lambda\left(-4 \kappa \bar{e}+p^{2} X_{H}\left(X_{H}+2 Y_{H}\right) \pi^{2}\right)\right]
$$

The following results follow straightforwardly:

Lemma 10. In a Type II agency, the optimal level of politicization and optimal promotion standard are:

$$
\pi^{*}\left(p, Y_{H}, Y_{L}, X_{H}\right)=\left\{\begin{array}{c}
1 \text { if } p<p^{*} \\
\frac{X_{H}+2 Y_{L}+p\left(Y_{H}-Y_{L}\right)}{(1-p)\left(X_{H}+2 Y_{L}\right)} \text { if } p^{*} \leq p \leq p^{* *} \\
0 \text { if } p>p^{* *}
\end{array}\right.
$$




$$
\bar{e}^{*}\left(p, Y_{H}, Y_{L}, X_{H}, k\right)=\left\{\begin{array}{c}
\frac{\lambda p^{2} X_{H}\left(X_{H}+2 Y_{H}\right)}{4[(1+3 \lambda) k-(1+\lambda) \kappa]} \text { if } p<p^{*} \\
-\frac{\lambda p^{2} X_{H}\left(Y_{H}-Y_{L}\right)^{2}}{\left(X_{H}+2 Y_{L}\right) 4[(1+3 \lambda) k-(1+\lambda) \kappa]} \text { if } p^{*} \leq p \leq p^{* *} \\
\frac{X_{H}\left(X_{H}+2\left(p\left(Y_{H}-Y_{L}\right)+Y_{L}\right)\right) \lambda}{4[(1+3 \lambda) k-(1+\lambda) \kappa]} \text { if } p>p^{* *}
\end{array}\right.
$$

where $p^{*}=-\frac{Y_{L}}{Y_{H}-Y_{L}}$ and $p^{* *} \equiv-\frac{X_{H}+2 Y_{L}}{Y_{H}-Y_{L}}$.

Proof. The proof is virtually identical to that of Lemma 7, and is omitted for brevity.

The results for politicization are the same as for Type I agencies, however those for the promotion standard differ slightly.

Proposition 11. In a Type II agency the following is an equilibrium. The Boss offers the contract $\left(w_{c}, w_{m}, \bar{e}^{*}\right)$ and then chooses a level of politicization $\pi^{*}$, where $w_{c}=\frac{s_{c}+s_{m}-\bar{e}^{2}(\kappa-k)}{2}$, $w_{m}=s_{i}-\beta(p) \bar{e}=w_{c}+\kappa \bar{e}^{2}-\beta(p) \bar{e}$ and $\bar{e}^{*}$ and $\pi^{*}$ are defined in Lemma 10. Both slackers and zealots accept the contract and both invest in expertise to the promotion standard $\bar{e}^{*}$ and are promoted. Slackers then exit the agency while zealots remain and undertake policy making effort $a^{*}$ defined in Lemma 2. Promoted zealots recommend a project if and only if they discover $X>0$. If central review reveals $Y>0$ the Boss accepts the project. Otherwise he accepts the recommendation if and only if $p \geq p^{*}$.

Proof. Follows from above Lemmata. QED

\section{Examples}

It may be useful to examine briefly two simple examples that illustrate screening and sorting in action. ${ }^{11}$

Screening in a Type I Agency.-Consider a Type I agency. Type I agencies operate in an environment in which outside employers do not particularly value the expertise acquired by managers in the agency. More formally, we require that at $\bar{e}, s_{i}-w_{c}<c(\bar{e})$. The preceding section has argued that such agencies can motivate zealots to acquire costly expertise and assume supervisory roles in the agency while screening out slackers from the top ranks of the agency. This is important because slackers, unlike zealots, shirk their policy work. 
Table 6: EU of Slacker-type in Type I Agency

\begin{tabular}{ccc}
\hline \hline & Stay & Exit \\
\hline Invest & .42 & 1.02 \\
Don't Invest & $1.1 *$ & 1.05 \\
\hline \hline
\end{tabular}

Table 7: EU of Zealot-type in Type I Agency

\begin{tabular}{ccc}
\hline \hline & Stay & Exit \\
\hline Invest & $1.1 *$ & 1.02 \\
Don't Invest & 1.1 & 1.05 \\
\hline \hline
\end{tabular}

The following example shows the screening equilibrium at work. In the example, the values for the parameters are: $X_{H}=1 / 2, Y_{H}=1, Y_{L}=-1, p=2 / 3, k=1 / 36, s_{c}=1 / 2$, $s_{m}=6 / 10, s_{i}=2 / 3$. In the example $p^{*}<p<p^{* *}$ (using the appropriate definitions, $1 / 2<2 / 3<3 / 4)$. Thus, politicization should take an "intermediate" value rather a corner solution of 0 or 1 .

In fact, using the formulae derived earlier, we calculate that the Boss offers the contract $\left(\bar{e}=8 / 3, w_{c}=.55, w_{m}=.62\right)$ and then politicizes the agency to the level $\pi^{*}=1 / 3$. Thus, the agency offers higher entry-level wages than does the private sector. Because the cost of training to the promotion standard $\bar{e}$ is $k \bar{e}^{2}=.20$ the agency is a Type I agency (we require $s_{i}-w_{c}<c(\bar{e})$ which here is $\left..67-.55<.20\right)$.

Will these wages and promotion standard induce screening, given the level of politicization and outside wage? In other words, will a slacker decline to invest in expertise and remain with the agency, while a zealot does invest, receive a promotion into the policy making ranks, and remain with the agency? Tables 2 and 3 indicate the expected utilities of slackers and zealots as they make decision about investment and exit. It is (relatively) straightforward to calculate the values of the expected utilities in the example. These are shown in Tables 6 and 8.

First consider the slacker. The screening equilibrium requires him not to invest in expertise and to remain in the agency as a clerk. As shown, this is clearly the best option for the slacker. The wages received by a slacker who follows the prescribed actions leave 
him exactly indifferent between a public sector career and a private sector one $\left(\right.$ as $s_{c}+s_{m}=$ $\left.1.1=2 w_{c}\right)$.

Now consider the zealot. The screening equilibrium requires the zealot to invest in expertise, become a manager, and remain with the agency. As shown, a zealot has no profitable deviation from these choices. Indeed, the managerial wage has been set so that a zealot is just indifferent between seeking promotion and remaining a clerk, given the cost of training up to the promotion standard.

The key in constructing the equilibrium is that the zealot prizes the policy making job more than does the slacker, because he expects to derive job satisfaction from setting policy in a job that would otherwise be vacant. As shown, the zealot's net return from investment and promotion, 1.1, is considerably larger than that of the slacker, .42. This reflects the policy returns so valued by zealots.

Sorting in a Type II Agency. - Now consider a Type II agency. Type II agencies operate in an environment in which outside employers highly value the expertise acquired by managers in the agency. More formally, we require that at $\bar{e}, s_{i}(\bar{e})-w_{c}>c(\bar{e})$. (Our parameterization of the $s_{i}(\bar{e})$ and $c(\bar{e})$ functions guarantees that this requirement is satisfied for any value of $\bar{e}>0$ when $\kappa>k$.) The preceding section has argued that Type II agencies can set wages and promotion standards that motivate zealots and slackers to sort themselves from one another. In particular, wages and standards can be set so that both will acquire costly expertise, but only the zealot will remain with the agency. The slacker will depart for pastures he sees as greener.

We retain the same parameters from the preceding example. However, now the outside wage $s_{i}$ is not fixed but reflects the employee's acquisition of expertise, as demonstrated by agency promotion. In addition, the equilibrium requires a specification of $\lambda$, the percentage of zealots in the agency's clerks. In this example we assume $\lambda=1 / 2$. Finally, we assume $\kappa=1 / 25$

Using the formulae derived earlier, we calculate the Boss now offers the contract $(\bar{e}=$ 
Table 8: EU of Slacker-type in Type II Agency

\begin{tabular}{ccc}
\hline \hline & Stay & Exit \\
\hline Invest & .93 & $1.1 *$ \\
Don't Invest & .96 & .98 \\
\hline \hline
\end{tabular}

Table 9: EU of Zealot-type in Type II Agency

\begin{tabular}{ccc}
\hline \hline & Stay & Exit \\
\hline Invest & $1.1 *$ & 1.1 \\
Don't Invest & .96 & .98 \\
\hline \hline
\end{tabular}

$\left.25 / 13, w_{c}=.48, w_{m}=.78\right)$ and then politicizes the agency to the level $\pi^{*}=2 / 3$. To promoted employees, the private sector offers the wage $s_{i}=.95$, which is considerably higher than the wage the agency pays its promoted policy makers. In addition, the agency offers a somewhat lower entry-level wage than does the private sector. The cost of training to the level $\bar{e}$ is $k \bar{e}^{2}=.10$. The agency is indeed a Type II agency (we require $s_{i}-w_{c}>c(\bar{e})$ which here is $.95-.48>.10)$.

Will these wages and promotion standard induce sorting, given the level of politicization and outside wage? In other words, will both slackers and zealots invest in expertise and receive promotion, with the zealots opting to remain in the agency as policy makers while the slackers depart for the private sector? Again we calculate the expected utilities of different actions for the actors and display them, here in Tables 8 and 9. As shown, the best choice for the slacker is to invest and depart. The prescribed action for the zealot is to invest and stay, and as indicated he has no incentive to deviate from this action. The agency wage has been set so that a promoted zealot is just indifferent between staying and going. However, a zealot does much better staying than would a slacker (1.1 versus .93). As the agency economizes at its available margins, both slackers and zealots are indifferent between public and private careers. 


\section{Micro-Foundations of the Competence-Control Trade-off}

As has been widely discussed in recent years, public agencies display a sharp trade-off between administrative competence and political control . Lewis 2008 for example employs a measure of bureau performance and finds lower performance in bureaus with many political appointees. Many mechanisms might give rise to a competence-control trade-off, for instance, the simple replacement of high-quality civil servants with lower-quality but more politically loyal appointees. However, the model highlights one mechanism and thus micro-founds the trade-off. In particular, as policy disagreement between the Boss and subordinates increases (that is, as $p$ falls), the Boss alters agency design, increasing politicization and lowering promotion standards - and thus human capital among public sector managers while adjusting wages accordingly.

First consider the effect of policy agreement $p$ on politicization $\pi$. Using the results in the two propositions,lower levels of policy agreement $p$ lead to higher levels of politicization. This effect is shown in Figure 7. ${ }^{12}$ As shown there, politicization decreases (weakly) monotonically as policy agreement $(p)$ increases. The three politicization regimes are clear in the figure: when the likelihood of disagreement is high (the high conflict environment), the Boss fully politicizes so that he audits every recommendation of the subordinate; when disagreement is moderate, levels of politicization are moderate; and when the likelihood of disagreement is low, the Boss does not politicize at all.

Now consider the effect of policy agreement on the promotion standard, as shown in Figure 8 for a Type II agency. In both Type I and Type II agencies, expertise increases monotonically as the likelihood of policy agreement increases. The effect of the jump at the cross-over from a high-conflict environment to a low-conflict environment is clear in the figure; it occurs in both types of agencies.

One can combine both figures to show the politicization-expertise frontier. This is done in Figure 9 for a Type II agency. The figure shows the $(\bar{e}, \pi)-$ tuple for various values of $p$ ranging from 0 to 1 . As shown, high values of agreement result in low politicization and 


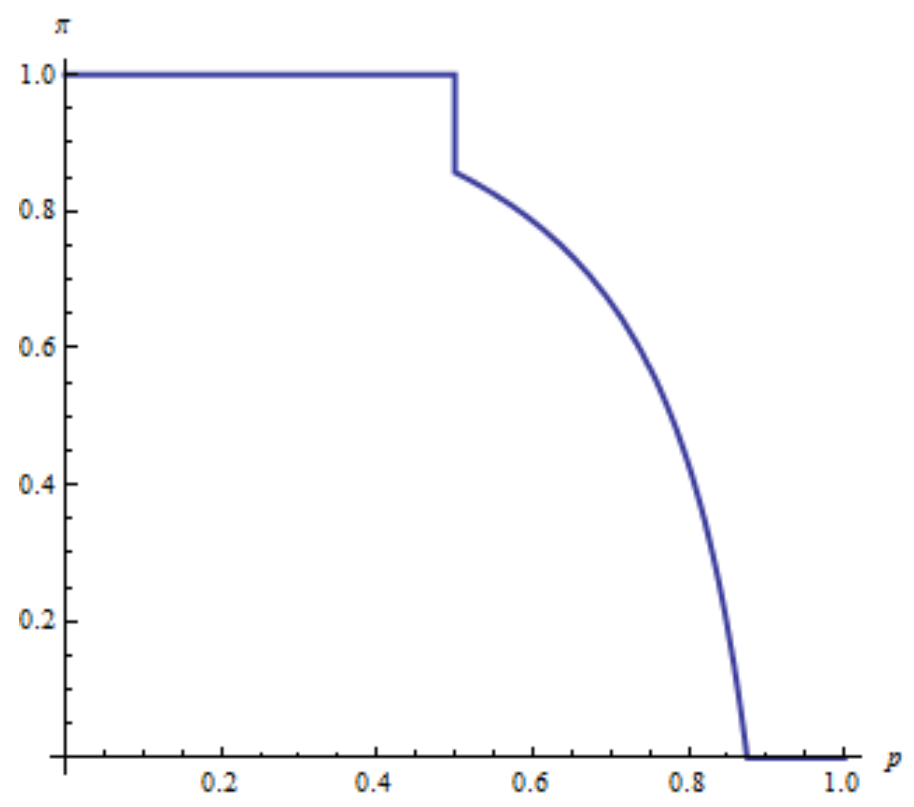

Figure 7: Policy Agreement and Politicization

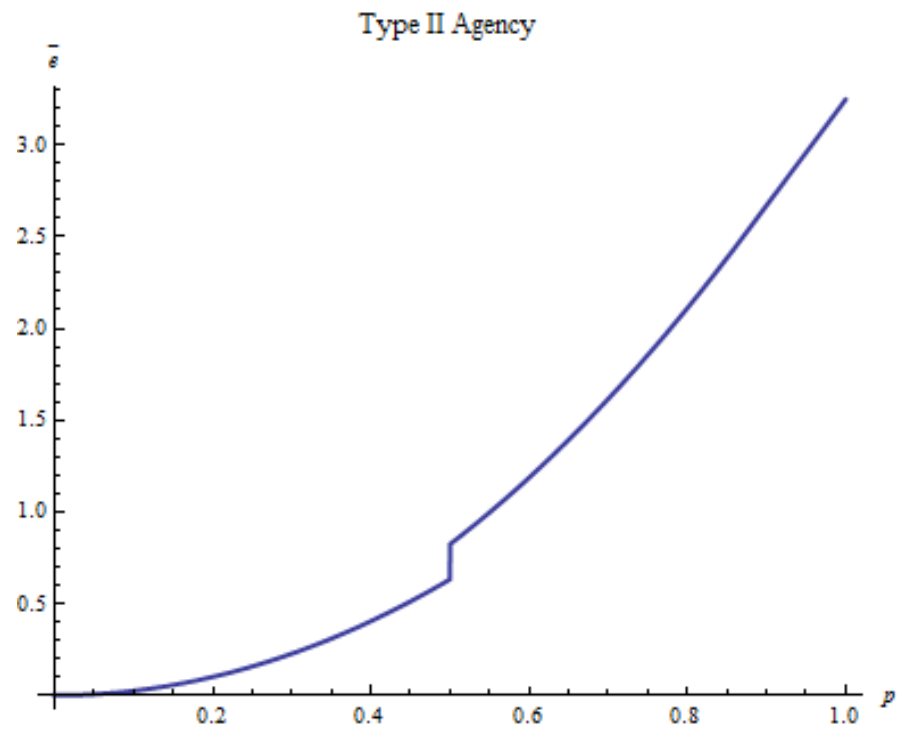

Figure 8: Policy Agreement and the Promotion Standard 


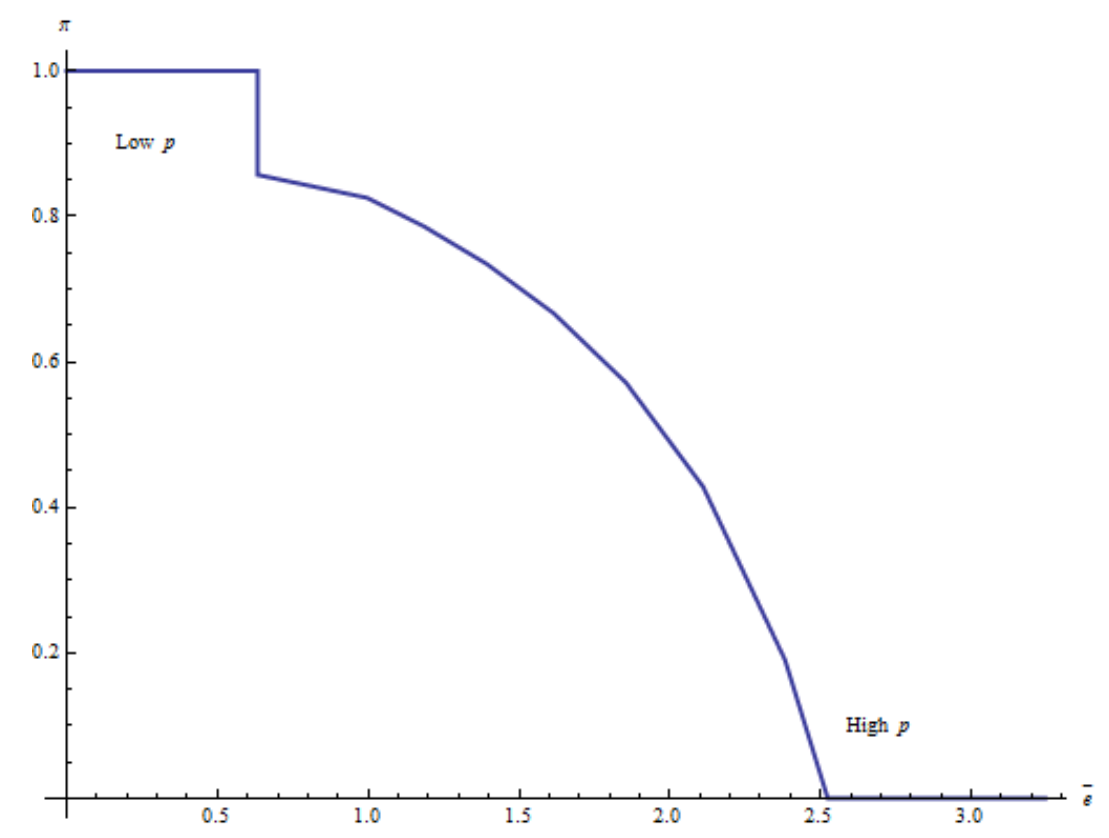

Figure 9: The Competence-Control Tradeoff

a high promotion standard, leading to public sector managers with high levels of human capital. In contrast, low levels of policy agreement lead to high levels of politicization and a low promotion standard, hence, poorly skilled public managers.

The logic underlying the frontier shown in Figure 9 is fairly straightforward. First, high conflict (low $p$ ) drives the Boss to politicize decision-making, to protect himself from policy recommendations with which he disagrees. This degrades job satisfaction for intrinsically motivated managers so the Boss must increase the managerial wage, if he maintains the same promotion standard. But in addition, the low level of policy agreement between the Boss and the manager makes the work effort of the manager less valuable to the Boss, so he is unwilling to pay highly for their work. Consequently, the Boss lowers the promotion standard.

\section{Discussion and Conclusion}

We have argued that public agencies face a pervasive dual-contracting problem: it is difficult for agency leaders and civil servants to contract on worker performance, and hard for 
politicians to refrain from self-interested meddling in agency policy-making. Both problems influence the ability of public agencies to recruit, train, motivate, and retain expert employees, employees whose performance affects public agency performance. We have explored how wage structures and promotion standards respond to, and partially mitigate, the dual contracting problem by sorting "slackers" from "zealots." The analysis highlights the differences between what we have called Type I agencies, where managers have few attractive outside opportunities, and Type II agencies, where high-level manager have lucrative opportunities in the private sector. The analysis also provides micro-foundations for the trade-off between political control and agency competence.

Although the model contains many stages it makes a series of integrated predictions not only about wage structures and promotion standards, but human capital acquisition, career paths, politicization levels, employee work effect, and agency performance including rates of agency policy innovation. The model provides a framework for exploring how changes in outside wages, shocks to policy disagreement between political overseers and career managers due to changes in party control of government, and shocks to agency wages from wage freezes have systematic impacts on the operation of public agencies, and different impacts across Type I and Type II agencies. These rich predictions might well be taken to data, especially data from agencies' internal personnel records.

The model has implications for efforts to reform public agencies. Disappointment with public agency performance has led elected officials world-wide to pursue fundamental reorganizations of public agencies. Elected officials typically seek measures that facilitate greater political control of the bureaucracy, modifying public sector personnel systems (Suleiman 2003). The model suggests that efforts to enhance political control can have perverse consequences for agency performance. The prospect of increased meddling will lead to reduced worker effort and ultimately lower promotion standards. Lower promotion standards imply less expert managers, a flatter salary structure, and fewer high-quality projects. Reform programs targeting personnel systems - entry and managerial pay, benefits, promotion stan- 
dards, and so on - thus have strong implications for the ability of the agency to cultivate cadres of top quality managers.

\section{A Longer Proofs}

\section{Lemma 1}

Proof. First consider the manager's recommendation strategy $r()$. In light of Equation 1, any deviation from the indicated strategy brings a loss to a zealot-type manager given the indicated decision strategy $d^{*}(\sigma)$, and in fact would do so whenever there is a positive probability the Boss accepts the proposed policy project. Because a slacker-type manager is indifferent between $X_{L}$ and $X_{H}$, he has no incentive to deviate to "recommend" if either $X=X_{L}$ or $X=X_{H}$. (As will become clear in the next Lemma, $X=X_{H}$ is actually off the equilibrium path if the manager is a slacker.) If one assumes an $\epsilon$ cost to the manager from a positive recommendation, then a slacker has a disincentive to deviate from the indicated strategy regardless of $X$. Now consider the Boss's decision strategy. Clearly, if informed the Boss will reject the recommended project if $Y=Y_{L}$ and accept if $Y=Y_{H}$. If uninformed, Boss will accept if $\mu Y_{H}+(1-\mu) Y_{L}>0$, where $\mu$ denotes Boss's posterior belief that $Y=Y_{H}$ given being uninformed and manager's recommendation strategy. From Bayes' Rule conditional on a positive recommendation, given the manager's recomendation strategy and that $\theta$ is independent of the state $(X, Y), \mu=p$. Hence, Boss will accept when

uninformed if $p Y_{H}+(1-p) Y_{L}>0 \Rightarrow p \geq-\frac{Y_{L}}{Y_{H}-Y_{L}}$. If $p<-\frac{Y_{L}}{Y_{H}-Y_{L}}$ Boss will reject when uninformed. QED

\section{Lemma 4}

Proof. First consider slackers $(\theta=0)$. A slacker invests only to be promoted since he receives no satisfaction from policy-making per se. Consequently, if he invests at all, he invests the minimum to be promoted, $\bar{e}$. Promotion will be worthwhile only if the best post-promotion opportunity is sufficiently remunerative to offset training costs; otherwise the slacker will 
remain a clerk, either in the public or private sectors, depending on which clerkship pays more. The investment strategy of slackers follows immediately. Second, consider zealots $(\theta=1)$. The following point is important. A zealot's expected utility from being promoted and remaining with the agency is $w_{m}+\beta e-k e^{2}$, which is concave in $e$ and reaches a maximum of $w_{m}+\frac{1}{4} \frac{\beta^{2}}{k}$ at $e=\frac{\beta}{2 k}$. Given this, behavior in a Type I agency is straightforward: If $\bar{e}>\frac{\beta}{2 k}$ but if even so, promotion is better than non-promotion, the zealot will invest to $\bar{e}$. If $\bar{e}<\frac{\beta}{2 k}$ and if promotion is better than non-promotion, the zealot will invest to $\frac{\beta}{2 k}$. If non-promotion is better than promotion, the zealot will not invest at all as doing gains him nothing and is costly. Behavior in a Type II agency is somewhat more complex. If $\bar{e}>\frac{\beta}{2 k}$ and promotion is better than non-promotion, then whether staying or going is the better post-promotion option, the zealot only invests to $\bar{e}$ as further investment only hurts him. If $\bar{e}<\frac{\beta}{2 k}$ a zealot will invest in expertise beyond $\bar{e}$ to $e=\frac{\beta}{2 k}-$ but only if doing so and remaining with the agency is better than investing just to the promotion standard and leaving for the private sector (that is, if $w_{m}+\frac{1}{4} \frac{\beta^{2}}{k} \geq s_{o}(\bar{e})-k \bar{e}^{2}$ ) and such an investment is better than remaining a clerk either in the public or private sectors $\left(w_{m}+\frac{1}{4} \frac{\beta^{2}}{k} \geq \max \left\{s_{c}, w_{c}\right\}\right)$. However, if the outside wage is sufficiently high, then the zealot invests just to the promotion standard and departs (again, if doing so is better than remaining a clerk). Finally, if remaining a clerk is better than the best post-promotion option, the zealot remains a clerk. QED

\section{Lemma 6}

Proof. 1a. The conjectured equilibrium requires for slackers $2 w_{c} \geq s_{c}+s_{m}$, which implies $w_{c} \geq \frac{s_{c}+s_{m}}{2} .1 \mathrm{~b}$. If slackers are indifferent then $w_{c}=\frac{s_{c}+s_{m}}{2}$ and $s_{c}+s_{m}=2 w_{c}$. The conjectured equilibrium requires for zealots $w_{c}+w_{m}+\beta \bar{e}-k \bar{e}^{2} \geq s_{c}+s_{m}$, and the result follows immediately. 2a. Given indifference, the conjecture equilibrium requires both $w_{c}+w_{m}+$ $\beta \bar{e}-k \bar{e}^{2}=s_{c}+s_{m}$ and $w_{c}+s_{i}-k \bar{e}^{2}=s_{c}+s_{m}$. Hence $w_{c}+w_{m}+\beta \bar{e}-k \bar{e}^{2}=w_{c}+s_{i}-k \bar{e}^{2}$, or $w_{m}+\beta \bar{e}=s_{i}$. 2b. The conjectured equilibrium requires that $w_{c}+s_{i}-k \bar{e}^{2}=s_{c}+s_{m}$. Clearly if $s_{i}-k \bar{e}^{2}$ varies in $\bar{e}$ then $w_{c}$ must adjust to maintain the equality. QED 
Lemma 7 (Optimal promotion standard and politicization in Type I agencies).

Proof. First, note that because $\pi$ is a probability it is bounded by 0 and 1 , while $e$ must be non-negative. Hence it is necessary to consider corner solutions where $\pi=1$ or 0 and $e=0$. However, for interior solutions one need only examine the first order conditions for maximizing Equation 11 (where $p \in\left[-\frac{Y_{L}}{Y_{H}-Y_{L}}, 1\right]$ ) and (where $p \in\left[0,-\frac{Y_{L}}{Y_{H}-Y_{L}}\right]$ ). For the former, the relevant partial derivatives are:

$$
\begin{gathered}
\frac{\partial}{\partial \pi} E u_{2}^{B}(\cdot)=-\frac{X_{H} \bar{e}}{2}(1-p)\left[(1-p)\left(X_{H}+2 Y_{L}\right) \pi-\left(p\left(Y_{H}-Y_{L}\right)+\left(X_{H}+2 Y_{L}\right)\right)\right] \\
\frac{\partial}{\partial e} E u_{2}^{B}(\cdot)=\frac{X_{H}(1-(1-p) \pi)}{2}\left[\left(p Y_{H}+(1-\pi)(1-p) Y_{L}\right)+\frac{1}{2} X_{H}(1-(1-p) \pi)\right]-2 k \bar{e}
\end{gathered}
$$

Setting both to zero and solving simultaneously yields $\pi^{*}\left(p, Y_{H}, Y_{L}, X_{H}\right)=\frac{X_{H}+2 Y_{L}+p\left(Y_{H}-Y_{L}\right)}{(1-p)\left(X_{H}+2 Y_{L}\right)}$ and $\bar{e}^{*}\left(p, Y_{H}, Y_{L}, X_{H}, k\right)=-\frac{p^{2} X_{H}\left(Y_{H}-Y_{L}\right)^{2}}{\left(X_{H}+2 Y_{L}\right) 8 k}$ respectively. Note that these solutions require $X_{H}+2 Y_{L}<0$. In addition, $\pi=\frac{X_{H}+2 Y_{L}+p\left(Y_{H}-Y_{L}\right)}{(1-p)\left(X_{H}+2 Y_{L}\right)}=0$ at $p=-\frac{X_{H}+2 Y_{L}}{Y_{H}-Y_{L}} \equiv p^{* *}$, implying $\pi=0$ for values of $p>p^{* *}$. But, given $\pi=0 \frac{\partial}{\partial e} E u_{2}^{B}(\cdot)=\frac{-8 e k+X_{H}\left[X_{H}+2\left(p\left(Y_{H}-Y_{L}\right)+Y_{L}\right]\right.}{4}$ implying $e=\frac{X_{H}\left(X_{H}+2\left(p\left(Y_{H}-Y_{L}\right)+Y_{L}\right)\right)}{8 k}$.Now consider Equation 11 when $p<p^{*}$. In this case the relevant partial derivatives are:

$$
\begin{gathered}
\frac{\partial}{\partial \pi} E u_{2}^{B}(\cdot)=\frac{e p^{2} X_{H}\left(X_{H}+2 Y_{H}\right) \pi}{2} \\
\frac{\partial}{\partial e} E u_{2}^{B}(\cdot)=\frac{-8 e k+p^{2} X_{H}\left(X_{H}+2 Y_{H}\right) \pi^{2}}{4}
\end{gathered}
$$

Note that the first of these is positive, implying a corner solution $\pi=1$. Given this, $e=\frac{p^{2} X_{H}\left(X_{H}+2 Y_{H}\right)}{8 k}$ QED

Lemma 10 (Optimal promotion standard and politicization in Type II agencies)

Proof. The proof is very similar to that of Lemma 7. The Boss's maximand is indicated in the body of the paper. 


\section{B Notation}

\begin{tabular}{|c|c|}
\hline Notation & Definition \\
\hline$s_{c}$ & Entry-level wage in the private-sector \\
\hline$s_{m}$ & Second-period (expected) wage in the private-sector \\
\hline$s_{i}$ & Private sector wage for promoted public-sector employee, either $s_{c}$ or $s_{o}$ \\
\hline$s_{o}$ & Outside wage available post-promotion in Type II agencies, $s_{o}=s_{c}+\kappa e^{2}$ \\
\hline$w_{c}$ & Entry-level wage in the public-sector \\
\hline$w_{m}$ & Managerial wage for promoted public-sector employee \\
\hline$p$ & Policy agreement between public employee and Boss, $\operatorname{pr}\left(Y_{H} \mid X_{H}\right)$ \\
\hline$X$ & Value to employee of project, either $X_{L}$ or $X_{H}$ \\
\hline$Y$ & Value to Boss of project, either $Y_{L}$ or $Y_{H}$ \\
\hline$\pi$ & Politicization level, probability Boss learns $Y$ via central review, set by Boss \\
\hline$E Y$ & Expected value of policy-making to Boss \\
\hline$r$ & Manager recommends the project $(r=1)$ or does not $(r=0)$ \\
\hline$\sigma$ & Element of Boss's information set $\left\{Y_{H}, Y_{L}, \varnothing\right\}$ ( $\varnothing$ connotes uninformative review) \\
\hline$d$ & Boss accepts project $(d=1)$ or rejects project $(d=0)$ \\
\hline$e$ & Level of investment in expertise of public-sector employee \\
\hline $\bar{e}$ & Promotion standard in the public sector, set by Boss \\
\hline$a$ & Policy-making effort, probability of worker creating an $X_{H}$ project \\
\hline$\theta$ & Type of employee, either slacker $(\theta=0)$ or zealot $(\theta=1)$ \\
\hline$v$ & Value to Boss of clerk services \\
\hline$\beta_{1}, \beta_{2}$ & Intrinsic motivation of zealots in high $p$ and low $p$ environments, from policy-making \\
\hline$c(e ; k)$ & Cost of investment in expertise is $c(e)=k e^{2}$ \\
\hline$c(a ; e)$ & Cost policy-making action, $c(a ; e)=\gamma a$ where $\gamma=1 / e$ \\
\hline$\lambda$ & Proportion of employees entering Type II agencies who are zealots \\
\hline
\end{tabular}

Table 10: Notation 


\section{REFERENCES}

Aghion, Phillip and Jean Tirole. 1997. "Formal and Real Authority in Organizations," Journal of Political Economy 105:1-29.

Akerlof, George and Rachel Kranton. 2005. "Identity and the Economics of Organizations," Journal of Economc Perspectives 19(1):9-32.

Baker, George. 2002. "Distortion and Risk in Optimal Incentive Contracts," Journal of Human Resources 37(4): pp.

Baker, George, Robert Gibbons, and Kevin Murphy. 1999. "Informal Authority in Organizations," Journal of Law, Economics, and Organization, 15(1).

Besley, Timothy and Maitreesh Ghatak. 2005. "Competition and Incentives with Motivated Agents," American Economic Review 95(3): 616-636.

Besley, Timoty and Maitreesh Ghatak 2008. "Status Incentives," American Economic Review: Papers and Proceedings 98(2): 206-211.

Bolton, Patrick and Mathias Dewatripont. 2004. Contract Theory. MIT Press.

Carpenter, Daniel. 2001. The Forging of Bureaucratic Autonomy: Reputations, Networks and Policy Innovation in Executive Agencies, 1862-1928. Princeton University Press.

Carpenter, Daniel. 2010. Reputation and Power: Organizational Image and Pharmaceutical Regulation at the FDA. Princeton University Press.

Downs, Anthony. 1967. Inside Bureaucracy. Little, Brown.

Dull, Matthew, Patrick S. Roberts, Michael S. Keeney, Sang Ok Choi. 2012. "Appointee Confirmation and Tenure: The Succession of U.S. Federal Agency Appointees, 1989-2009." Public Administration Review 72(6):902-13. 
Epstein, David and Sharyn O'Halloran. 1999. Delegating Powers: A Transaction Cost Politics Approach to Policy Making Under Separate Powers. Cambridge University Press.

Gailmard, Sean, and John W. Patty. 2007. "Slackers and Zealots: Civil Service, Policy Discretion, and Bureaucratic Expertise," American Journal of Political Science 51(4): 873889.

Gibbons, Robert and John Roberts. 2013. Handbook of Organizational Economics. Princeton University Press.

Golden, Marissa. 2000. What Motivates Bureaucrats? Politics and Administration During the Reagan Years. Columbia University Press.

Heclo, Hugh. 1977. A Government of Strangers: Executive Politics in Washington. Brookings Institution Press.

Hirsch, Alex. 2011. "Experiment and Persuasion in Political Organizations," working paper, Woodrow Wilson School and Department of Politics, Princeton University.

Holmstrom, Bengt and Paul Milgrom. 1991. "Multi-task Principal-Agent Analyses: Incentive Contracts, Asset Ownership, and Job Design," Journal of Law, Economics, and Organization $7: 24-52$.

Huber, John and Nolan McCarty. 2004. "Bureaucratic Capacity, Delegation, and Political Reform," American Political Science Review 98 (3): 481-94.

Huber, John and Charles Shipan. 2002. Deliberate Discretion? The Institutional Foundations of Bureaucratic Autonomy. Cambridge University Press.

Johnson, Ronald N. and Gary D. Leibcap. 1994. The Federal Civil Service System and the Problem of Bureaucracy: The Economics and Politics of Institutional Change. University of Chicago Press. 
Kaufman, Herbert. 1960. The Forest Ranger: A Study in Administrative Behavior. Resources for the Future.

Kaufman, Herbert. 1981. The Administrative Behavior of Federal Bureau Chiefs. Brookings Institution Press.

Lazear, Edward. 1998. Personnel Economics for Managers. John Wiley and Sons.

Oyer, Paul and Edward Lazear. 2013. "Personnel Economics," pp. 479-519 in Gibbons and Roberts (eds.) 2013.

Lazear, Edward and Sherwin Rosen. 1981. "Rank-Order Tournaments as Optimum Labor Contracts," Journal of Political Economy 89(5) 841-64.

Levy, Brian and Pablo Spiller 1994, "The Institutional Foundations of Regulatory Commitment: A Comparative Analysis of Telecommunications Regulation", The Journal of Law, Economics and Organization, October, pp. 201-246.

Lewis, David. 2008. The Politics of Presidential Appointments: Political Control and Bureaucratic Performance. Princeton UP.

MacLeod, W. Bentley. 2007. "Repubations, Relationships, and Contract Enforcement," Journal of Economic Literature 45: 595-628.

Maranto, Robert. 1998. "Thinking the Unthinkable in Public Administration: A Case for Spoils in the Federal Bureaucracy," Administration and Society 29 (6):623-42.

Maranto, Robert. 2001. "Why the President Should Ignore Calls to Reduce the Number of Political Appointees," The Heritage Foundation Backgrounder (1413).

McCarty, Nolan. 2004. "The Appointments Dilemma," American Journal of Political Science 48(3): 413-428. 
McCubbins, Mathew, Roger Noll,and Barry Weingast. 1989. "Structure and Process, Politics and Policy: Administrative Arrangements and the Political Control of Agencies," Virginia Law Review 75:431-pp.

Moe, Terry M. 1985. "The Politicized Presidency". In The New Direction in American Politics, edited by J. E. Chubb and P. E. Peterson. Washington, DC: Brookings Institution Press.

Moe, Terry. 2011. Special Interest: Teachers Unions and America's Public Schools. Brookings Institution Press.

O'Connell, Anne Joseph. 2009. "Vacant Offices: Delays in Staffing Top Agency Positions." 82 Southern California Law Review 913.

Perry, James L. and Lois R. Wise. 1990. "The Motivational Bases of Public Service," Public Administration Review 50: 367-373.

Prendergast, Canice. 1993. "The Role of Promotion in Inducing Specific Human Capital Acquisition," The Quarterly Journal of Economics 108(2):523-534.

Prendergast, Canice. 2008. "Intrinsic Motivation and Incentives," American Economic Review: Papers and Proceedings 98:2: 201-205.

Roberts, John. 2007. The Modern Firm: Organizational Design for Performance. Oxford University Press.

Shaw, Kathryn 2009. "Insider Econometrics: A Roadmap with Stops Along the Way," Labour Economics, 2009

Suleiman, Ezra. 2003. Dismantling Democratic States. Princeton, NJ: Princeton University Press.

Ting, Michael. 2011. "Organizational Capacity," Journal of Law, Economics, and Organization 27(2): 245-271. 
Van den Steen, Eric. 2010. "On the Origin of Shared Beliefs (and Corporate Cultures)" RAND Journal of Economics 41(4): 617-648.

Vlaicu, Razvan and Alex Whalley. 2012. "Hierarchical Accountability in Government: Theory and Evidence," http://papers.ssrn.com/sol3/papers.cfm?abstract_id=1925005

Waldman, Michael. 2013. "Theory and Evidence in Internal Labor Markets," pp. 520-571in Gibbons and Roberts (eds.) 2013.

Weingast, Barry, and William J. Marshall (1988). "The Industrial Organization of Congress; or Why Legislatures, Like Firms, Are Not Organized as a Market" JPE 96: 132-63.

West, Martin. 2009. "Bargaining with Authority: The Political Origins of Public Sector Collective Bargaining," Unpublished manuscript.

Williamson, Oliver E. 1983. "Credible Commitments: Using Hostages to Support Exchange," American Economic Review, September 1983, 73, 519-40.

Williamson, Oliver E. 1985. The Economic Institutions of Capitalism. Free Press: New York. Williamson, Oliver E. 1996. The Mechanisms of Governance. Oxford University Press: London.

Wilson, James Q. 1989. Bureaucracy: What Government Agencies Do and Why They Do it. Basic Books. 


\section{Notes}

*Princeton University; Duke and NBER, and NBER; Vanderbilt University, respectively. We thank Bob Gibbons, Guido Tabellini, Bentley MacLeod, Pablo Spiller, Bob Powell, Steve Tadelis, Oliver Williamson, Noam Yuchtman, Ernesto Dal Bo, Ken Shepsle, Nolan McCarty and seminar participants at Vanderbilt, Duke, Princeton, the Institute for Advanced Study, and the Haas School of Business (Berkeley) for helpful comments. The research was funded by NSF Grant 1061575, 1061600, and 1061512.

${ }^{1}$ Following the arguments in Baker, Gibbons, Murphy 1999, we do not regard politicization and meddling as contractable: a pledge not to politicize is not credible, and if the Boss has installed a centralized review capacity, he will use it.

${ }^{2}$ In contrast with Aghion and Tirole 1997, we do not allow the Boss to independently craft his own policy projects. Although such a degree of centralizaiton sometimes occurs, it simply reproduces the same principal-agent tensions we study. Instead we closely follow Baker, Gibbons, Murphy 1999.

${ }^{3}$ For simplicity we assume $w_{c}$ is net of effort costs in the clerk job.

${ }^{4}$ This sequence of play allows us to consider not only the exit decision of a non-promoted subordinate, but that of a promoted manager in the face of a new Boss who increases politicization. The promotion outcome becomes public knowledge; the employee's exact performance evaluation does not so that a private sector employer can condition its wage on the former but not the latter.

${ }^{5}$ Although we use the word "recommendation," the game structure is not equivalent to cheap talk. The failure to recommend a project constrains the Boss's action space: he cannot opt for any project.

${ }^{6}$ The Boss may not really suffer disutility from paying wages to the Subordinate as government agencies do not get to retain earnings (for a discussion see Wilson 1989). But at least for agency design, we imagine the Boss trying to conserve on wages, perhaps due to congressional pressure. 
${ }^{7}$ In the language of typical Human Resources personnel evaluations, the employee "Takes collective responsibility for total organization's successes and failures within the scope of influence."

${ }^{8}$ If an "in and outer" zealot felt some residual or discounted decision ownership, then this feeling could effect his exit decision. In particular, if his position were immediately filled with another capable manager, then exit would appear more attractive. However, if he were likely to be replaced by a poor decision-maker, exit would be less attractive.

${ }^{9}$ In equilibrium, in Type I agencies the zealots will be promoted and become managers while the slackers will remain clerks. In Type II agencies, both will be promoted.

${ }^{10}$ Note that we do not allow Type I agencies to compete with Type II agencies over employees. That is, the market for potential meat inspectors (say) is distinct from the market for potential anti-trust lawyers.

${ }^{11}$ The examples require considerable calculation. A Mathematica program to calculate all the values in the example will be placed on Cameron's webpage.

${ }^{12}$ The figures in this section assume $Y_{H}=1, Y_{L}=-1, X_{H}=\frac{1}{4}, k=\frac{1}{36}$, and $\kappa=\frac{1}{25}$. Thus $p^{*}=\frac{1}{2}$ and $p^{* *}=\frac{7}{8}$. 